Psychological Medicine

\title{
The impact of childhood deprivation on adult neuropsychological functioning is associated with ADHD symptom persistence
}

\author{
--Manuscript Draft--
}

\begin{tabular}{|c|c|}
\hline Manuscript Number: & PSM-D-19-01143R2 \\
\hline Full Title: & $\begin{array}{l}\text { The impact of childhood deprivation on adult neuropsychological functioning is associated } \\
\text { with ADHD symptom persistence }\end{array}$ \\
\hline Article Type: & Original Article \\
\hline Corresponding Author: & $\begin{array}{l}\text { Dennis Golm, Ph.D. } \\
\text { University of Southampton } \\
\text { Southampton, UNITED KINGDOM }\end{array}$ \\
\hline \multicolumn{2}{|l|}{$\begin{array}{l}\text { Corresponding Author Secondary } \\
\text { Information: }\end{array}$} \\
\hline Corresponding Author's Institution: & University of Southampton \\
\hline \multicolumn{2}{|l|}{$\begin{array}{l}\text { Corresponding Author's Secondary } \\
\text { Institution: }\end{array}$} \\
\hline First Author: & Dennis Golm, Ph.D. \\
\hline \multicolumn{2}{|l|}{ First Author Secondary Information: } \\
\hline \multirow[t]{7}{*}{ Order of Authors: } & Dennis Golm, Ph.D. \\
\hline & Sagari Sarkar, Ph.D. \\
\hline & Nuria Mackes, Ph.D. \\
\hline & Graeme Fairchild, Ph.D. \\
\hline & Mitul A. Mehta, Ph.D. \\
\hline & Michael Rutter, Ph.D. \\
\hline & Edmund J. Sonuga-Barke, Ph.D. \\
\hline \multicolumn{2}{|l|}{$\begin{array}{l}\text { Order of Authors Secondary } \\
\text { Information: }\end{array}$} \\
\hline Manuscript Region of Origin: & UNITED KINGDOM \\
\hline Abstract: & $\begin{array}{l}\text { Background: Institutional deprivation in early childhood is associated with } \\
\text { neuropsychological deficits in adolescence. Using } 20 \text {-year follow-up data from a unique } \\
\text { natural experiment - the large-scale adoption of children exposed to extreme deprivation } \\
\text { in Romanian institutions in the } 1980 \text { s -we examined, for the first time, whether such } \\
\text { deficits are still present in adulthood and whether they are associated with deprivation- } \\
\text { related symptoms of attention-deficit/hyperactivity disorder (ADHD) and autism spectrum } \\
\text { disorder (ASD). Methods: Adult neuropsychological functioning was assessed across five } \\
\text { domains (inhibitory control, emotion recognition, decision-making, prospective memory } \\
\text { and IQ) in } 70 \text { previously-institutionalized adoptees (mean age }=25.3,50 \% \text { female) and } 22 \\
\text { non-deprived UK adoptees (comparison group, mean age }=24.6,41 \% \text { female). ADHD and } \\
\text { ASD symptoms were assessed using parent-completed questionnaires. Results: Early } \\
\text { institutionalization was associated with impaired performance on all tasks in adulthood. } \\
\text { Prospective memory deficits persisted after controlling for IQ. ADHD and ASD symptoms } \\
\text { were positively correlated. After controlling for ASD symptoms, ADHD symptoms remained } \\
\text { associated with deficits in IQ, prospective memory, proactive inhibition, decision-making } \\
\text { quality and emotion recognition. ASD symptoms were not independently associated with } \\
\text { neuropsychological deficits when accounting for their overlap with ADHD symptoms. } \\
\text { Multiple regression analysis revealed that the link between childhood deprivation and } \\
\text { adult ADHD symptoms was statistically explained by deprivation-related differences in } \\
\text { adult IQ and prospective memory. Conclusions: These results represent some of the most } \\
\text { compelling evidence to date of the enduring power of early, time-limited childhood } \\
\text { adversity to impair long-term neuropsychological functioning across the lifespan - effects } \\
\text { that are linked specifically to deprivation-related adult ADHD symptoms. }\end{array}$ \\
\hline
\end{tabular}


The impact of childhood deprivation on adult neuropsychological functioning is associated with ADHD symptom persistence

Dennis Golm ${ }^{1}$, Sagari Sarkar², Nuria K. Mackes ${ }^{3}$, Graeme Fairchild ${ }^{4}$, Mitul A. Mehta ${ }^{5}$, Michael Rutter $^{6}$, ERA Young Adult Follow Up study team* and Edmund J. Sonuga-Barke**3,7

${ }^{1}$ Centre for Innovation in Mental Health, School of Psychology, University of Southampton, UK

2. Cognitive Neuroscience \& Neuropsychiatry Section, University College London.

${ }^{3}$ Department of Child and Adolescent Psychiatry, Institute of Psychiatry, Psychology \& Neuroscience, King's College London, UK

${ }^{4}$ Department of Psychology, University of Bath, UK

${ }^{5}$ Department of Neuroimaging, Institute of Psychiatry, Psychology and Neuroscience, King's College London, UK

${ }^{6}$ MRC Social Genetic \& Developmental Psychiatry Centre, Institute of Psychiatry, Psychology \& Neuroscience, King's College London, UK

${ }^{7}$ Department of Child \& Adolescent Psychiatry, Aarhus University, Denmark.

*The ERA young adult follow-up team is Edmund Sonuga-Barke, Mark Kennedy, Jana Kreppner, Nicky Knights, Robert Kumsta, Barbara Maughan and Wolff Schlotz.

**Correspondence should be addressed to Professor Edmund Sonuga-Barke, Department of Child and Adolescent Psychiatry- P085, Institute of Psychiatry, Psychology and Neuroscience, King's College London, 16 De Crespigny Park, London, SE5 8AF, UK. Email: edmund.sonuga-barke@kcl.ac.uk

Word count: 5403 


\begin{abstract}
Background: Institutional deprivation in early childhood is associated with neuropsychological deficits in adolescence. Using 20-year follow-up data from a unique natural experiment - the largescale adoption of children exposed to extreme deprivation in Romanian institutions in the 1980s -we examined, for the first time, whether such deficits are still present in adulthood and whether they are associated with deprivation-related symptoms of attention-deficit/hyperactivity disorder (ADHD) and autism spectrum disorder (ASD).
\end{abstract}

Methods: Adult neuropsychological functioning was assessed across five domains (inhibitory control, emotion recognition, decision-making, prospective memory and IQ) in 70 previously-institutionalized adoptees (mean age $=25.3,50 \%$ female) and 22 non-deprived UK adoptees (comparison group, mean age $=24.6,41 \%$ female). ADHD and ASD symptoms were assessed using parent-completed questionnaires.

Results: Early institutionalization was associated with impaired performance on all tasks in adulthood. Prospective memory deficits persisted after controlling for IQ. ADHD and ASD symptoms were positively correlated. After controlling for ASD symptoms, ADHD symptoms remained associated with deficits in IQ, prospective memory, proactive inhibition, decision-making quality and emotion recognition. ASD symptoms were not independently associated with neuropsychological deficits when accounting for their overlap with ADHD symptoms. Multiple regression analysis revealed that the link between childhood deprivation and adult ADHD symptoms was statistically explained by deprivationrelated differences in adult IQ and prospective memory.

Conclusions: These results represent some of the most compelling evidence to date of the enduring power of early, time-limited childhood adversity to impair long-term neuropsychological functioning across the lifespan - effects that are linked specifically to deprivation-related adult ADHD symptoms. Keywords: institutional deprivation, childhood neglect, maltreatment, prospective memory, ADHD 
Childhood neglect is associated with long-term negative developmental (Vasileva and Petermann, 2018), mental health (Norman et al., 2012; Vasileva and Petermann, 2018) and neuropsychological outcomes (Kavanaugh et al., 2017). However, the interpretation of such associations is hindered by design limitations common to observational studies. For instance, many studies rely on retrospective reports of neglect (Hardt and Rutter, 2004; Norman et al., 2012) occurring in biological families of individuals either specifically identified or self-selected as a result of the development of mental health problems. This makes it difficult to disentangle early adversity from familial genetic and environmental risk (including continuing adversity) and subsequent psychopathology.

The English and Romanian Adoptees (ERA) study utilizes a unique natural experiment - the largescale adoption of infants and young children from the Romanian institutions after the fall of Ceaușescu's regime in 1989 - with a prospective design, thus addressing some of these methodological problems to strengthen causal inference. Adoptees entered institutions in the first weeks of life and were then exposed to up to 43 months of global deprivation, a particularly severe type of neglect marked by limited cognitive stimulation, minimal social interaction with adult carers, and poor diet and hygiene (Sonuga-Barke et al., 2017). They were subsequently adopted into well-resourced UK families where they received high-quality care. This led to a precisely-timed, sudden and dramatic change in their rearing environment, which was largely determined by historical circumstances. Crucially, this meant that the duration of deprivation exposure was unlikely to be confounded with variations in either genetic or pre-institutional risk and/or post-adoption circumstances. Further, because the adoptees entered the study based on their deprivation exposure, rather than because they displayed the adverse effects of deprivation (e.g., psychopathology), the association between deprivation exposure and neuropsychological impairment can be disentangled from deprivation related psychopathology. 
The ERA study has followed-up the adoptees at ages 4, 6, 11 and 15 years, and most recently in young adulthood (aged 23-25 years). For nearly all of the adoptees, an initial devastating effect of deprivation on development was recorded at the time of adoption. This was followed, for many, by marked recovery by age 6 years (Rutter, 1998). Nevertheless, a substantial minority of adoptees, especially those exposed to $>6$ months deprivation, presented with a heterogeneous yet distinctive pattern of neurodevelopmental problems in comparison to non-deprived adoptees. Most pronounced were symptoms of attention-deficit/hyperactivity disorder (ADHD; Kenne_____et__al._2016)), autism spectrum disorder (ASD; Rutter _et_al. 2007) and disinhibited social engagement (DSE - indiscriminate friendliness and a lack of social boundaries; Kennedy et al. 2017). These problems have persisted to a striking degree through to adulthood, in spite of exposure to positive and nurturing family environments in the intervening period (> 20 years in some cases) (Kennedy et al., 2017; SonugaBarke et al., 2017). This persistence, has led to the hypothesis that these problems are the result of deep-seated changes in underlying neuropsychological processes (Rutter and O’Connor, 2004; McCrory et al., 2017; Nelson et al., 2019). In support of this hypothesis, deprivation-specific neurodevelopmental difficulties were in many cases accompanied by cognitive impairment, as indexed by low IQ - although a degree of catch-up in IQ has occurred across childhood and adolescence (Sonuga-Barke et al., 2017). Extended childhood deprivation was associated with deficits on neuropsychological tests of social cognition and executive function at age 11 (Colvert et al., 2008c). Furthermore, we have recently reported MRI data confirming deprivation-related reductions in total brain volume and regional alterations in frontal and temporal lobes (Mackes et al., 2020).

Our study is the first to provide data on the persistence of adverse neuropsychological effects into adulthood, as all previous research on post-institutionalized individuals have included either children or adolescents (Colvert et al., 2008c, 2008a; Bos et al., 2009; McDermott et al., 2013, 2013; Merz et al., 2013; Moulson et al., 2015; Almas et al., 2016; Bick et al., 2017; Wade et al., 2019). We also investigated the relationship between deprivation-related effects on neuropsychological functioning 
and two of the hallmark neurodevelopmental effects of institutional deprivation - ADHD and ASD symptoms. DSE was not included in this analysis because it was limited almost exclusively to those individuals with extended deprivation.

We selected four neuropsychological domains for investigation, in addition to IQ. This selection process was guided by evidence from previous waves of the ERA study, clinical interviews with the adult adoptees performed during the most recent assessment wave (the ERA Young Adult Follow-up), and prior evidence suggesting a link between these domains and early neglect, childhood maltreatment in general and/or ADHD or ASD symptoms. These domains were: (i) Inhibitory control - this is impaired in individuals who have experienced institutional deprivation (McDermott et al., 2013; Merz et al., 2013) and is associated with both ADHD (Huizenga et al., 2009; Lipszyc and Schachar, 2010; Miller et al., 2012; Miranda-Casas et al., 2013) and ASD (Geurts et al., 2014). At the age 11 wave of the ERA Study, inhibitory control deficits statistically mediated the relationship between deprivation and ADHD symptoms (Colvert et al., 2008c). It is now recognized that inhibitory control can be separated into two elements - proactive inhibition, the recruitment of executive resources in preparation to withhold a response before its initiation to a target, and reactive inhibition, the ability to stop a response after its initiation in response to a target (Meyer and Bucci, 2016). Proactive and reactive inhibition represent equally important aspects of inhibitory based executive control. However, most tasks are unable to distinguish between these different elements of inhibition. We therefore decided to use a cued Go-NoGo task to isolate proactive inhibition from the conventional analysis of commission errors on non-cued tasks which would index failures of reactive inhibition. To date no studies of proactive inhibition have been conducted in maltreated samples. In children with ADHD (Pani et al., 2013; van Hulst et al., 2018) and ASD (van Hulst et al., 2018), deficits seem to be primarily limited to reactive inhibition. However, adult studies are lacking. (ii) Prospective memorydeficits in prospective memory, the ability to remember to undertake an action in the future, were reported by ERA participants during clinical interviews conducted before we designed this study. 
Previous reports suggest that adolescents with a history of maltreatment are impaired in prospective (Lin et al., 2017) and other forms of memory _. Prospective memory has also been found to be impaired in children and adults with ADHD (Fuermaier et al., 2013; Talbot et al., 2018) and ASD (Sheppard et al., 2018). (iii) Emotion recognition impairments are commonly reported in children and adolescents following institutional deprivation (Colvert et al., 2008b; Nelson et al., 2013; Moulson et al., 2015; Bick et al., 2017; Doretto and Scivoletto, 2018). Individuals with ADHD and ASD also display emotion recognition deficits (Lozier et al., 2014; Borhani and Nejati, 2018). (iv) Decisionmaking about outcomes varying in amount and probability is impaired in maltreated children (Guyer $e t$ al., 2006), children with a history of early stress (Hanson et al., 2016; Birn et al., 2017), and adolescents exposed to institutional deprivation (Mehta et al., 2010). Additionally, it is impaired in individuals with ADHD (Sonuga- Barke et al., 2016; Sorensen et al., 2017) though findings are inconsistent in ASD (Dillon et al., 2009; Carlisi et al., 2017).

We studied performance on neuropsychological tests measuring these domains to address five questions in relation to institutional deprivation and the associated outcomes of ADHD and ASD symptoms:

(i) Is time-limited institutional deprivation related to neuropsychological deficits in early adulthood?

(ii) If present, were these effects most pronounced in those individuals exposed to the most extended periods of deprivation?

(iii) Are these effects simply due to deficits in general cognitive ability (IQ), which we know exist in the extended deprivation group?

(iv) Are deprivation-related ADHD and ASD symptoms associated with neuropsychological deficits and are these effects independent of one another? 
(v) Is the association between childhood institutional deprivation and adult ADHD and/or ASD symptoms explained by the former's association with adult IQ or other neuropsychological deficits?

\section{Methods and Materials}

\section{Participants}

The current sample included 70 adult Romanian adoptees who experienced between 3 and 41 months of institutional deprivation (mean age $=25.3$ years; $50 \%$ female) and a control group of 23 UK neverinstitutionalized adoptees (mean age $=24.6$ years; $39 \%$ female) - representing $49 \%$ and $44 \%$ of the original sample, respectively. To assess whether selective attrition had occurred, we compared all ERABIS participants ( $\mathrm{n}=93)$ with ERA participants who did not take part in ERABIS $(\mathrm{n}=103)$ in terms of deprivation status, IQ and ADHD and ASD symptoms at age 6 years. The two groups did not differ on any variable (robust t-tests with $20 \%$ trimmed means and bias-corrected bootstrapped confidence intervals; ps>.16; see Supplement 1). One UK adoptee was excluded from all subsequent analyses due to low IQ $(<60)$, reducing the UK adoptee group to 22 participants (mean age $=24.6,41 \%$ female).

\section{Measures}

Inhibitory control. In the cued Go/No-Go (GNG) task (Criaud et al., 2012), participants had to either press a button when a "go" target (white circle) was present or inhibit their response to a "no-go" target (white "X") presented on each trial in the center of the computer screen. The response interval was $1000 \mathrm{~ms}$ (stimulus presentation duration: 950ms, 50ms inter-stimulus interval). Two conditions, each with 108 trials, were compared to isolate an individual's ability to mobilize and maintain resources required for an upcoming inhibitory response (i.e., proactive inhibition). A "possible 
inhibition" trial was indicated by a pre-target red cross (+) cue $(2000 \mathrm{~ms}$ or $6000 \mathrm{~ms})$ to indicate that either a "no-go or "go" target would be presented (both n=48). This cue alerted the participant to prepare to inhibit their response. This was compared to a control "never inhibit" condition where a white cross (+) indicated that only "go" targets $(\mathrm{n}=81)$ would be presented and thus proactive mobilization of inhibitory resources was not required. Proactive inhibition was indicated by a slowing of reaction times to correct "go" target responses for "possible inhibition" compared to the "never inhibit" cues. The remaining trials in each condition ( $\mathrm{n}=12$ for "possible inhibition" and $\mathrm{n}=27$ for the "never inhibit") were null trials in which no target was presented. The dependent variables were proactive inhibition and commission errors - the failure to withhold a reaction to a stop target.

Prospective memory. The Memory for Intentions Screening Test (MIST) (Raskin, 2009) involved a word-search puzzle as a distractor task during which participants were requested to remember to respond to instructions delivered throughout the task either at specified times or to pre-determined events at either short (2 minutes) or long (15 minutes) intervals. Responses could be made in response to verbal (e.g. "In two minutes, please tell me two things you forgot to do this week") or action-based cues (e.g. "When I give you a red pen, sign your name on your paper."). The dependent variable was the total sum score with higher scores indicating better prospective memory functioning.

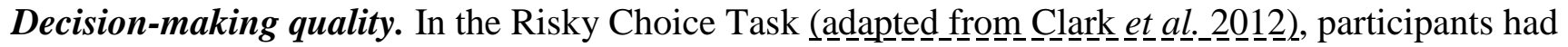
to choose between two roulette wheels offering different sums of money and different probabilities of receiving a gain versus a loss. Each wheel was divided into 8 segments, each segment contained a number depicting a possible win (+) or loss (-) amount - marked in different colors. The amount available to be won or lost and the probability of winning (indexed by the number of win versus loss segments) was systematically varied across trials. At the beginning of each new block, participants started with 100 points. On each trial after a 1000ms delay, "please choose now" appeared on the screen and the participant had to select a wheel. There was no time limit. After the choice was made, the selected wheel was presented on its own and a ticker span around the wheel for $2000 \mathrm{~ms}$ before landing on a segment. The amount of money won or lost was then displayed for $2000 \mathrm{~ms}$ and added to 
or subtracted from the total score, followed by a 2000ms inter-stimulus-interval. Eight trial types involved a choice between a control gamble and an experimental gamble. The experimental gamble could result in either a larger gain or loss with varying probabilities ( 25 or $75 \%$ ), while the control gamble could result in either a small gain or loss (see supplement 2). Overall, there were 76 trials divided into four blocks. There were two dependent variables: Decision-making quality - the probability of choosing the most valuable wheel -was computed by first weighing the probability with which each participant chose the experimental gamble with its expected value and then averaging across those newly computed values to create a single score $\left(\bar{x}=\frac{1}{n}\left(\sum\left(F_{i} * E_{i}\right)\right)\right)$. Risk proneness - the average probability of choosing the experimental gamble $\left(\bar{x}=\frac{1}{n}\left(\sum\left(F_{i}\right)\right)\right.$.

Emotion recognition. The emotion recognition task was taken from the EMOTICOM battery (Bland et al., 2016), which had two conditions. In the experimental condition, one of four emotional faces (happy, sad, anger or fear; each $\mathrm{n}=21$ ) was presented for $\sim 500 \mathrm{~ms}$ in the center of the screen and participants selected the emotional label (happy, sad, anger or fear) that best described it. The dependent variable was the number of correctly identified expressions expressed as a percentage. Because they were highly correlated $(\mathrm{rsSpearman} \geq .34$, all $\mathrm{ps} \leq .001)$ the scores for individual negative emotions (anger, sadness, fear) were combined to produce a single emotion recognition score. The recognition score for happy faces was excluded as it did not correlate with the negative emotion recognition scores (rsspearman $\leq .04$, all ps $\geq$.703). During the control condition neutral faces of individuals aged across the lifespan (child, young adult, middle-aged or elderly; each $n=4$ ) were presented, and participants were required to assign age labels to each stimulus (child, young adult, middle aged or elderly). As there were no effects of deprivation or ADHD/ASD symptoms on performance on the age recognition task (all ps $\geq .057$, see supplement 3 ), we present only the results for the negative emotion trials from the condition.

Cognitive ability. IQ was assessed using the Wechsler Abbreviated Scale of Intelligence (Wechsler, 2011), which consists of 4 subscales - two verbal -(vocabulary and similarities) and two performance (block design and matrix reasoning). 
ADHD and ASD symptoms. Parents reported on participants' ADHD symptoms using the two ADHD subscales of the Conners Behavior Rating Scales, a reliable and well-validated instrument (Conners et al., 2011). Ten items measured DSM-5-based inattention symptoms and 10 items assessed hyperactivity/impulsivity symptoms. Parents reported on ASD symptoms using a 15-item version of the Social Communication Questionnaire (SCQ; Rutter, Bailey, \& Lord, 2003), recently adapted for use with adults (Kennedy et al., 2016, 2017). It has 3 scales: social reciprocal interaction, social communication and repetitive and stereotyped behavior (see Sonuga-Barke et al., 2017 for the items retained). All items were answered on a "yes/no" basis. ADHD and ASD parent reports were chosen over self-reports for two reasons despite the fact that many young people were not living at home at the time of assessment. First, because there are doubts about the validity of self-reports of ADHD symptoms (Du Rietz et al., 2016) and ASD (Pearl_et_al.__2017); Second, to maintain continuity with previous analyses in the ERA study (Stevens et al., 2008; Kennedy et al., 2017; Sonuga-Barke et al., 2017). Crucially, there was no difference in correlations between symptoms and neuropsychological test performance for those living and those not living at home (see supplement 4).

\section{Procedure}

Clinical data (including parent-report) were collected during home visits to the families as part of the ERA Young Adult Follow-up (described in Kennedy et al. 2016). Neuropsychological data were collected at the Centre for Neuroimaging Sciences, King's College London, as part of the ERA Brain Imaging Study. Neuropsychological testing was undertaken by trained researchers as part of an 8-hour assessment conducted either over two consecutive days or one day depending on participants' preferences and perceived capacity. Completion of the tasks described above took approximately 2 hours, and the task order was varied in order to reduce the impact of order effects. We asked participants to abstain from cigarettes and caffeinated drinks on the testing day and, if prescribed stimulant medication, for 24 hours before testing. In addition to a lunch break, breaks were provided as required by the participant. Participants provided written informed consent before the ERA and ERABIS assessments. Ethical approval for ERABIS was obtained from the University of 
Southampton's Ethics Committee and the Camberwell and St Giles NHS Research Ethics Committee (14/LO/0477). Ethical approval for the ERA Young Adult Follow-up was obtained from the University of Southampton's Ethics Committee.

\section{Statistical analysis}

SPSS 25 (IBM Corp, 2017) and R 3.3 and R 3.6.1 (R Core Team, 2016, 2019) utilizing the WSR2 package (robust tests) and the RVAideMemoire package (e.g. partial Spearman correlations) were used for data analysis. All analyses were False Discovery Rate (FDR) corrected for multiple comparisons (Benjamini and Hochberg, 1995). First, robust t-tests (Wilcox, 2016) using 20\% trimmed means and bias-corrected bootstrapped confidence intervals (1000 bootstraps as recommended

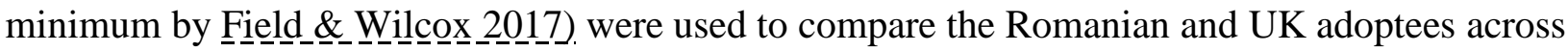
neuropsychological domains. Second, we used Spearman correlations with bootstrapped confidence intervals (to ensure a high level of stringency we used 1000 bootstraps) to examine links between duration of deprivation and neuropsychological performance. Third, to test whether observed effects could be explained by deficits in general cognitive ability, we used a robust regression method to regress IQ onto the neuropsychological scores and then compared the residuals of the neuropsychological scores. Fourth, we examined the associations between neuropsychological outcomes and ASD and ADHD symptom dimensions and their independence from each other using partial Spearman correlations with bootstrapped confidence intervals (1000 bootstraps; minimum number of bootstraps recommended by developer), adjusting for effects of ASD symptoms on the association between ADHD-related symptoms and neuropsychological function and vice versa. Finally, we tested whether the link between childhood deprivation and adult ADHD and/or ASD symptoms was explained by the former's association with adult neuropsychological performance (including IQ) using stepwise multiple regression. Deprivation status was included in step 1. All neuropsychological variables shown to be independently related to deprivation in the above analyses were then introduced at subsequent steps - one at a time - to assess their independent contribution to explaining the link between deprivation and symptom outcomes. The outcome variables were ADHD 
and/or ASD symptom scores, depending on whether they showed an independent association with neuropsychological functioning.

\section{Results}

Relative to non-deprived adoptees, Romanian adoptees had lower IQs, and displayed deficits in proactive inhibition, prospective memory, decision-making quality and emotion recognition $(\mathrm{p}<.05$, Table 1). The effects ranged from moderate to large in size for significant differences according to Wilcox (Wilcox, 2016). Duration of deprivation was not significantly correlated with any neuropsychological outcome within the Romanian group $\left(\mathrm{r}_{\text {Spearman }}=-.19\right.$ to $\mathrm{r}_{\text {Spearman }}=.07$, all $\mathrm{ps} \geq .112$; see supplement 6). Only the group effect for prospective memory remained significant after adjusting for IQ ( $<$ <.05, FDR; see Table 1). Table 2 reports the group differences for ADHD and ASD symptoms and correlations between ASD symptoms ADHD symptoms (and the ADHD subdimensions of inattention and hyperactivity/impulsivity) and neuropsychological test performance. A history of early deprivation had a moderate to large effect on the occurrence of neurodevelopmental symptoms in adulthood. ADHD symptoms were associated with lower IQ and deficits in prospective memory (moderate correlation) and emotion recognition (small correlation). When ASD symptoms were controlled for, all correlations with ADHD symptoms reported above remained significant and additional correlations with impaired decision-making quality and proactive inhibition emerged. ASD symptoms correlated with low IQ and impairment in prospective memory, proactive inhibition and emotion recognition. However, after controlling for ADHD symptoms none of these correlations remained significant. After FDR-correction, neuropsychological test performance was not significantly correlated with either self or parent-rated young adult emotional problems in any measured domain (see supplement 5). 
Only IQ and prospective memory met the criteria for predictors, and only ADHD symptoms met the criteria for outcomes, in the multiple regression analysis (Table 3). There was a strong association between deprivation status and adult ADHD symptoms when the former was introduced alone in step 1. prospective memory was introduced into the model in step 2. It was significantly associated with ADHD symptoms independent of deprivation status. Although deprivation status was still significantly associated with ADHD symptoms, the effect was substantially reduced in this case. IQ was then introduced into the model in step 3. Both IQ and prospective memory were significantly associated with ADHD symptoms - independently of one another. The association between deprivation and ADHD symptoms was no longer significant in this case. This suggests that the link between deprivation and ADHD symptoms was fully accounted for by the former variable's links with IQ and prospective memory.

\section{Discussion}

The ERA Study has shown that extended institutional deprivation experienced in early childhood has a long-term impact on neurodevelopmental outcomes in adulthood - with adult ADHD, ASD and DSE symptoms especially pronounced (Sonuga-Barke et al., 2017). Here we explore the long-term impact of deprivation on neuropsychological performance, and investigate whether deprivation-related neurodevelopmental outcomes are related to neuropsychological deficits, by studying links between deprivation and adult neuropsychological function across a range of domains predicted to be: (i) affected by deprivation; and (ii) linked to deprivation-specific neurodevelopmental problems. These domains were proactive inhibition, emotion recognition, decision-making quality and prospective memory - as well as general cognitive ability (indexed by IQ). There were several noteworthy findings. 
The first major finding was that early childhood institutional deprivation was associated with impairment in young adulthood across a broad range of neuropsychological domains - IQ, prospective memory, proactive inhibition, decision-making quality and emotion recognition. Analysis of the residuals obtained after regressing out IQ showed that, for emotion recognition, proactive inhibition, and decision-making quality these associations were attributable to deprivation-related deficits in general cognitive ability (i.e., IQ). However, this was not the case for prospective memory. It has been previously shown that IQ co-varies with a wide range of neuropsychological functions (Diaz-Asper $e t$ al., 2004) and our results confirm this for proactive inhibition, decision-making quality and emotion recognition in previously institutionalized young adults. Although it may not be surprising that the effect of deprivation on proactive inhibition is accounted for by lower IQ, our observation that this also contributed to group differences in emotion recognition was somewhat unexpected (see Bland et al. 2016). While our previous assessment at the age 11 follow-up (Colvert et al., 2008b) and a metaanalysis (Luke and Banerjee, 2013) support the existence of emotion recognition deficits in institutionally-deprived children and adolescents, many previous studies did not directly test the hypothesis that such deficits were part of a more general pattern of adversity-related cognitive impairment. One longitudinal study found that IQ mediated the effects of maltreatment on emotion recognition in adulthood (Young and Widom, 2014). This suggests that effects of maltreatment on emotion recognition - especially in adulthood - are small and, at least partly, reflect reductions in general cognitive ability, as indexed by IQ. The only domain of neuropsychological performance where no impact of institutional deprivation was observed was risk-proneness - there was no evidence that Romanian adoptees were either more risk seeking, or risk averse, than the UK adoptee comparison group. While few studies have looked at the more general effects of maltreatment on this form of decision-making quality, there are suggestions that more general social disadvantage may increase levels of risk taking (Petridou et al., 1997). The current findings may help to explain why extended deprivation is not associated with engagement in risky behaviors such as substance abuse in the ERA sample (manuscript in preparation). 
The association between IQ and institutional deprivation reported here, and its role in driving the effects of institutional deprivation on specific neuropsychological deficits in adulthood, appears to be at odds with evidence of almost complete remission of cognitive impairment by adulthood in the most severely deprived Romanian adoptees (those exposed to $>6$ months of deprivation (Sonuga-Barke $e t$ $a l ., 2017)$. On possibility is that lower IQ cases were selectively retained in ERABIS. However, our selective attrition analysis did not support this over-representation of lower IQ individuals in the ERABIS sample. However, IQ was included as a continuous measure in the current paper, instead of the categorical definition of cognitive impairment $(\mathrm{IQ}<80)$ in our previous reported finding of IQ deficits remitting with age. This suggests that, despite the observed recovery from cognitive impairment - with previously impaired individuals who had experienced extended deprivation moving into the normal range (i.e., above IQ above 80) - average IQ remained significantly lower in the Romanian adoptees.

The second major finding of note is that the severity of neuropsychological deficits in the Romanian adoptees was unrelated to the duration of deprivation. On the face of it, this is surprising given the step-like duration-related effects that have been reported previously by us for neurodevelopmental disorders such as ADHD and the remarkable persistence of such impairments from childhood to adulthood (Sonuga-Barke et al., 2017). Interestingly, in the Bucharest Early Intervention Project deprivation duration was also unrelated to the cognitive outcomes of memory performance and executive function in a group of Romanian children ( $~ 8$ years of age) with a history of institutionalization compared to never institutionalized children (Bos et al., 2009). The difference between the effects of deprivation on neurodevelopmental/clinical outcomes as reported previously, on one hand, and neuropsychological outcomes reported here on the other, suggests a complex and nondeterministic relationship between neuropsychological deficits (largely accounted for by IQ in this study) and clinical outcomes. This moves us away from simple causal models in which deprivation 
impairs neuropsychological functioning, which in turn drives disorder in a direct fashion (Morton and Frith, 1995). In fact, it would seem that neuropsychological deficits, at least as measured in adulthood, display an all-or-nothing relationship with institutional deprivation - with even children who suffered deprivation for a relatively short amount of time (i.e. 3 months) experiencing a negative effect on later functioning. Despite this, these children are almost completely indistinguishable from the nondeprived UK adoptees in terms of neurodevelopmental and clinical problems (Sonuga-Barke et al., 2017).

Third, neuropsychological performance across a number of domains was associated with ADHD but not ASD symptoms (once ADHD symptoms were controlled for). The finding of ADHD-related prospective memory deficits (Talbot et al., 2018) is consistent with the general neuropsychological literature on ADHD. It constituted the only neuropsychological domain that was related to both institutional deprivation and ADHD symptoms in univariate analyses, apart from IQ. Crucially, the multiple regression analysis suggested that the association between childhood deprivation and adult ADHD symptoms was fully explained by the link between deprivation and IQ and prospective memory - with each of these neuropsychological domains making an independent contribution. Prior research has identified similar deficits in prospective memory in adults with idiopathic (nondeprivation related) ADHD (Fuermaier et al., 2013, 2017; Altgassen et al., 2014; Talbot et al., 2018) that may be restricted to time-based prospective memory tasks (Altgassen et al., 2014). This suggests a degree of neuropsychological equivalence between deprivation- and non-deprivation-related ADHD symptoms, although the fact that the combination of deprivation, IQ and prospective memory explained $30 \%$ of the variance in ADHD symptoms provides support for a strong environmental influence on the neuropsychological underpinnings of ADHD in this sample. Relevant to this, a recent meta-analysis demonstrated working memory deficits in clinical and non-clinical samples of adults who had experienced early life stress (Goodman et al., 2019). 
The lack of correlations between ASD symptoms and neuropsychological performance was surprising given the literature suggesting that ASD is related to deficits in all of the domains assessed here (Geurts et al., 2014; Lozier et al., 2014; Carlisi et al., 2017; Sheppard et al., 2018). There are a number of possible explanations for this finding. First, deprivation-related ASD symptoms may be neuropsychologically distinct from ASD symptoms in non-deprived samples. Second, the current analysis focused on ASD symptoms as a dimension, rather than on individuals who met clinical cutoffs - so the severity of the ASD symptoms may not have been sufficient to lead to neuropsychological deficits and only a small number of individuals presented with high levels of ASD symptoms in the current sample. Finally, while the symptoms were rated through a validated questionnaire, this may not be sufficient to record the full extent to which individuals display features of ASD which would require a clinical assessment.

The present study had several distinctive features and strengths. In particular, it employed a natural experimental design to disentangle the impact of early, time-limited deprivation from the confounding effects of genetic and environmental risk factors that are frequently present in studies of maltreated children. It included a relatively large sample of severely deprived individuals with known durations of deprivation. As part of the ERA study we have also followed up a comparison group of nondeprived UK adoptees and they were included here to control for the effects of adoption per se. This allowed the effects to be studied in a design that reduces the risk of confounding by genetic factors or ongoing adversity. The study was also subject to several limitations. First, for practical reasons (i.e. time considerations) it could only focus on the range of neuropsychological domains presented here. Tasks measuring constructs such as Theory of Mind and temporal discounting would have been valuable additions given earlier evidence from the ERA study (Colvert et al., 2008c). The fact that all neuropsychological assessments were cross-sectional vis-à-vis clinical measures necessarily, limits our interpretation with regard to the causal relationships between neuropsychological performance and ADHD symptoms. Furthermore, we used a dimensional approach to analyzing ADHD and ASD 
symptoms and did not attempt to categorize individuals according to 'clinical' cut-offs. This is consistent with suggestions that ADHD should be viewed as a dimensional construct rather than a categorical diagnosis (McLennan, 2016). Third, the study lacked a non-deprived Romanian comparison group which limited our ability to disentangle effects of institutional care from other socio-economic disadvantages that Romanians were subject to in the harsh conditions of the 1980s. Nevertheless, the Bucharest Early Intervention Project included such a comparison group and still found children with a history of institutionalization to perform worse on neuropsychological tasks (Bos et al., 2009; Almas et al., 2016; Wade et al., 2019). The use of one source of information about ADHD and ASD information is also a potential limitation especially as we were reliant on parent ratings for both individuals who lived at home and those that had left home. However, as mentioned above our analysis showed no difference in parent ratings between these two groups. Finally, although this is an unusually large sample of such severely deprived individuals, it still provides only limited statistical power. It is therefore possible that we were unable to detect some important, though statistically small, effects. This constraint is particularly relevant to the multiple regression analyses, which typically require large sample sizes.

In conclusion, time-limited severe deprivation in early childhood has enduring effects on neuropsychological performance in young adulthood across a range of domains including prospective memory, proactive inhibition, decision-making quality and emotion recognition - but only the deficit in prospective memory was independent from deprivation-related effects on IQ. ADHD symptoms were related to a range of neuropsychological deficits, but only prospective memory explained variance beyond an influence of IQ. This is the first study of prospective memory deficits and their relationship to neurodevelopmental symptoms in previously institutionalized individuals. Such effects were observed over 20 years later, despite adoptees living with well-resourced and supportive families in the intervening period, demonstrating the long-term impact of adverse experiences during sensitive periods of development. 


\section{Acknowledgements}

We thank the families who took part in the study - this research would not have been possible without their continued support and dedication. The study team acknowledges the support of the National Institute for Health Research Clinical Research Network (NIHR CRN). We also thank Niall Bourke for his assistance with data collection and Laura Archer for her preparatory work on the Go-NoGo data.

\section{Financial support}

The Young Adult Follow-up was funded by the Economic and Social Research Council (E.S-B., RES062-23-3300). The Brain Imaging Study was funded by the Medical Research Council (E.S-B., M.M., G.F., MR/K022474/1). This study represents independent research that was part funded by the National Institute for Health Research (NIHR) Biomedical Research Centre at South London and Maudsley NHS Foundation Trust and King's College London.

\section{Conflicts of interest}

None.

\section{Ethical standards}

The authors assert that all procedures contributing to this work comply with the ethical standards of the relevant national and institutional committees on human experimentation and with the Helsinki Declaration of 1975, as revised in 2008. 


\section{References}

Almas AN, Degnan KA, Nelson CA, Zeanah CH, Fox NA (2016) IQ at age 12 following a history of institutional care: Findings from the Bucharest Early Intervention Project. Developmental psychology 52, $1858-1866$.

Altgassen M, Kretschmer A, Kliegel M (2014) Task Dissociation in Prospective Memory Performance in Individuals With ADHD. Journal of Attention Disorders 18, 617-624.

Benjamini Y, Hochberg Y (1995) Controlling the False Discovery Rate: A Practical and Powerful Approach to Multiple Testing. Journal of the Royal Statistical Society. Series B (Methodological) 57, 289300.

Bick J, Luyster R, Fox NA, Zeanah CH, Nelson CA (2017) Effects of early institutionalization on emotion processing in 12-year-old youth. Development and Psychopathology 29, 1749-1761.

Birn RM, Roeber BJ, Pollak SD (2017) Early childhood stress exposure, reward pathways, and adult decision making. Proceedings of the National Academy of Sciences 114, 13549-13554.

Bland AR, Roiser JP, Mehta MA, Schei T, Boland H, Campbell-Meiklejohn DK, Emsley RA, Munafo MR, Penton-Voak IS, Seara-Cardoso A, Viding E, Voon V, Sahakian BJ, Robbins TW, Elliott R (2016) EMOTICOM: A Neuropsychological Test Battery to Evaluate Emotion, Motivation, Impulsivity, and Social Cognition. Frontiers in Behavioral Neuroscience 10.

Borhani K, Nejati V (2018) Emotional face recognition in individuals withattention-deficit/hyperactivity disorder: a review article. Developmental Neuropsychology 43, 256-277.

Bos KJ, Fox N, Zeanah CH, Nelson CA (2009) Effects of early psychosocial deprivation on the development of memory and executive function. Frontiers in Behavioral Neuroscience $\mathbf{3}$.

Carlisi CO, Norman L, Murphy CM, Christakou A, Chantiluke K, Giampietro V, Simmons A, Brammer M, Murphy DG, Mataix-Cols D, Rubia K (2017) Shared and Disorder-Specific Neurocomputational Mechanisms of Decision-Making in Autism Spectrum Disorder and ObsessiveCompulsive Disorder. Cerebral Cortex 27, 5804-5816.

Clark L, Li R, Wright CM, Rome F, Fairchild G, Dunn BD, Aitken MRF (2012) Risk-avoidant decision making increased by threat of electric shock. Psychophysiology 49, 1436-1443.

Colvert E, Rutter M, Beckett C, Castle J, Groothues C, Hawkins A, Kreppner J, O'connor TG, Stevens S, Sonuga-Barke EJS (2008a) Emotional difficulties in early adolescence following severe early deprivation: Findings from the English and Romanian adoptees study. Development and Psychopathology 20.

Colvert E, Rutter M, Beckett C, Castle J, Groothues C, Hawkins A, Kreppner J, O'connor TG, Stevens S, Sonuga-Barke EJS (2008b) Emotional difficulties in early adolescence following severe early deprivation: Findings from the English and Romanian adoptees study. Development and Psychopathology 20.

Colvert E, Rutter M, Kreppner J, Beckett C, Castle J, Groothues C, Hawkins A, Stevens S, SonugaBarke EJS (2008c) Do Theory of Mind and Executive Function Deficits Underlie the Adverse Outcomes Associated with Profound Early Deprivation?: Findings from the English and Romanian Adoptees Study. Journal of Abnormal Child Psychology 36, 1057-1068. 
Conners CK, Pitkanen J, Rzepa SR (2011) Conners Comprehensive Behavior Rating Scale. In Encyclopedia of Clinical Neuropsychology, pp 678-680 Springer, New York, NY.

Criaud M, Wardak C, Ben Hamed S, Ballanger B, Boulinguez P (2012) Proactive Inhibitory Control of Response as the Default State of Executive Control. Frontiers in Psychology 3.

Diaz-Asper CM, Schretlen DJ, Pearlson GD (2004) How well does IQ predict neuropsychological test performance in normal adults? Journal of the International Neuropsychological Society 10, 82-90.

Dillon DG, Holmes AJ, Birk JL, Brooks N, Lyons-Ruth K, Pizzagalli DA (2009) Childhood Adversity Is Associated with Left Basal Ganglia Dysfunction During Reward Anticipation in Adulthood. Biological Psychiatry 66, 206-213.

Doretto V, Scivoletto S (2018) Effects of Early Neglect Experience on Recognition and Processing of Facial Expressions: A Systematic Review. Brain Sciences 8, 10.

Du Rietz E, Cheung CHM, McLoughlin G, Brandeis D, Banaschewski T, Asherson P, Kuntsi J (2016) Self-report of ADHD shows limited agreement with objective markers of persistence and remittance. Journal of Psychiatric Research 82, 91-99.

Field AP, Wilcox RR (2017) Robust statistical methods: A primer for clinical psychology and experimental psychopathology researchers. Behaviour Research and Therapy 98, 19-38.

Fuermaier ABM, Tucha L, Koerts J, Aschenbrenner S, Westermann C, Weisbrod M, Lange KW, Tucha O (2013) Complex Prospective Memory in Adults with Attention Deficit Hyperactivity Disorder. Plos One 8, e58338.

Fuermaier ABM, Tucha L, Koerts J, Weisbrod M, Lange KW, Aschenbrenner S, Tucha O (2017) Effects of methylphenidate on memory functions of adults with ADHD. Applied Neuropsychology: Adult 24, 199-211.

Geurts HM, van den Bergh SFWM, Ruzzano L (2014) Prepotent Response Inhibition and Interference Control in Autism Spectrum Disorders: Two Meta-Analyses. Autism Research 7, 407-420.

Goodman JB, Freeman EE, Chalmers KA (2019) The relationship between early life stress and working memory in adulthood: A systematic review and meta-analysis. Memory 27, 868-880.

Guyer AE, Kaufman J, Hodgdon HB, Masten CL, Jazbec S, Pine DS, Ernst M (2006) Behavioral Alterations in Reward System Function: The Role of Childhood Maltreatment and Psychopathology. Journal of the American Academy of Child \& Adolescent Psychiatry 45, 1059-1067.

Hanson JL, Albert D, Iselin A-MR, Carre JM, Dodge KA, Hariri AR (2016) Cumulative stress in childhood is associated with blunted reward-related brain activity in adulthood. Social Cognitive and Affective Neuroscience 11, 405-412.

Hardt J, Rutter M (2004) Validity of adult retrospective reports of adverse childhood experiences: review of the evidence. Journal of Child Psychology and Psychiatry 45, 260-273.

Huizenga HM, van Bers BMCW, Plat J, van den Wildenberg WPM, van der Molen MW (2009) Task Complexity Enhances Response Inhibition Deficits in Childhood and Adolescent AttentionDeficit/Hyperactivity Disorder: A Meta-Regression Analysis. Biological Psychiatry 65, 39-45. 
van Hulst BM, de Zeeuw P, Vlaskamp C, Rijks Y, Zandbelt BB, Durston S (2018) Children with ADHD symptoms show deficits in reactive but not proactive inhibition, irrespective of their formal diagnosis. Psychological Medicine 1-7.

Kavanaugh BC, Dupont-Frechette JA, Jerskey BA, Holler KA (2017) Neurocognitive deficits in children and adolescents following maltreatment: Neurodevelopmental consequences and neuropsychological implications of traumatic stress. Applied Neuropsychology-Child 6, 64-78.

Kennedy M, Kreppner J, Knights N, Kumsta R, Maughan B, Golm D, Rutter M, Schlotz W, SonugaBarke EJS (2016) Early severe institutional deprivation is associated with a persistent variant of adult attention-deficit/hyperactivity disorder: clinical presentation, developmental continuities and life circumstances in the English and Romanian Adoptees study. Journal of Child Psychology and Psychiatry 57, 1113-1125.

Kennedy M, Kreppner J, Knights NH, Kumsta R, Maughan B, Golm D, Hill J, Rutter M, SonugaBarke E (2017) Adult disinhibited social engagement (DSE) in adoptees exposed to extreme institutional deprivation: an examination of its clinical status and functional impact. British Journal of Psychiatry.

Lin P-Z, Bai H-Y, Sun J-W, Guo W, Zhang H-H, Cao F-L (2017) Association between child maltreatment and prospective and retrospective memory in adolescents: The mediatory effect of neuroticism. Child Abuse \& Neglect 65, 58-67.

Lipszyc J, Schachar R (2010) Inhibitory control and psychopathology A meta-analysis of studies using the stop signal task. Journal of the International Neuropsychological Society 16, 1064-1076.

Lozier LM, Vanmeter JW, Marsh AA (2014) Impairments in facial affect recognition associated with autism spectrum disorders: A meta-analysis. Development and Psychopathology 26, 933-945.

Luke N, Banerjee R (2013) Differentiated associations between childhood maltreatment experiences and social understanding: A meta-analysis and systematic review. Developmental Review 33, 1-28.

M Pearl A, M Edwards E, J Murray M (2017) Comparison of self-and other-report of symptoms of autism and comorbid psychopathology in adults with autism spectrum disorder. Contemporary Behavioral Health Care 2.

Mackes NK, Golm D, Sarkar S, Kumsta R, Rutter M, Fairchild G, Mehta MA, Sonuga-Barke EJS, on behalf of the ERA Young Adult Follow-up team (2020) Early childhood deprivation is associated with alterations in adult brain structure despite subsequent environmental enrichment. Proceedings of the National Academy of Sciences 117, 641-649.

Malarbi S, Abu-Rayya HM, Muscara F, Stargatt R (2017) Neuropsychological functioning of childhood trauma and post-traumatic stress disorder: A meta-analysis. Neuroscience and Biobehavioral Reviews $\mathbf{7 2}$, 68-86.

McCrory EJ, Gerin MI, Viding E (2017) Annual Research Review: Childhood maltreatment, latent vulnerability and the shift to preventative psychiatry - the contribution of functional brain imaging. Journal of Child Psychology and Psychiatry 58, 338-357.

McDermott JM, Troller-Renfree S, Vanderwert R, Nelson CA, Zeanah CH, Fox NA (2013) Psychosocial deprivation, executive functions, and the emergence of socio-emotional behavior problems. Frontiers in Human Neuroscience 7, 167.

McLennan JD (2016) Understanding attention deficit hyperactivity disorder as a continuum. Canadian Family Physician 62, 979-982. 

Hyporesponsive Reward Anticipation in the Basal Ganglia following Severe Institutional Deprivation Early in Life. Journal of Cognitive Neuroscience 22, 2316-2325.

Merz EC, McCall RB, Wright AJ, Luna B (2013) Inhibitory Control and Working Memory in PostInstitutionalized Children. Journal of Abnormal Child Psychology 41, 879-890.

Meyer HC, Bucci DJ (2016) Neural and behavioral mechanisms of proactive and reactive inhibition. Learning \& Memory 23, 504-514.

Miller M, Ho J, Hinshaw SP (2012) Executive Functions in Girls with ADHD Followed Prospectively into Young Adulthood. Neuropsychology 26, 278-287.

Miranda-Casas A, Baixauli-Fortea I, Colomer-Diago C, Rosello-Miranda B (2013) Autism and attention deficit hyperactivity disorder: similarities and differences in executive functioning and theory of mind. Revista De Neurologia 57, S177-S184.

Morton J, Frith U (1995) Causal modeling: A structural approach to developmental psychopathology. In Developmental psychopathology, Vol. 1: Theory and methods Wiley series on personality processes , pp 357-390 Oxford, England: John Wiley \& Sons.

Moulson MC, Shutts K, Fox NA, Zeanah CH, Spelke ES, Nelson CA (2015) Effects of early institutionalization on the development of emotion processing: a case for relative sparing? Developmental Science 18, 298-313.

Nelson CA, Westerlund A, McDermott JM, Zeanah CH, Fox NA (2013) Emotion recognition following early psychosocial deprivation. Development and psychopathology 25, 517-525.

Nelson CA, Zeanah CH, Fox NA (2019) How Early Experience Shapes Human Development: The Case of Psychosocial Deprivation. Neural Plasticity 2019, 1676285.

Norman RE, Byambaa M, De R, Butchart A, Scott J, Vos T (2012) The Long-Term Health Consequences of Child Physical Abuse, Emotional Abuse, and Neglect: A Systematic Review and MetaAnalysis. ed. M. Tomlinson PLoS Medicine 9, e1001349.

Pani P, Menghini D, Napolitano C, Calcagni M, Armando M, Sergeant JA, Vicari S (2013) Proactive and reactive control of movement are differently affected in Attention Deficit Hyperactivity Disorder children. Research in Developmental Disabilities 34, 3104-3111.

Petridou E, Zavitsanos X, Dessypris N, Frangakis C, Mandyla M, Doxiadis S, Trichopoulos D (1997) Adolescents in High-Risk Trajectory: Clustering of Risky Behavior and the Origins of Socioeconomic Health Differentials. Preventive Medicine 26, 215-219.

Raskin S (2009) Memory for Intentions Screening Test: Psychometric Properties and Clinical Evidence. vol 10 .

Rutter M (1998) Developmental Catch-up, and Deficit, Following Adoption after Severe Global Early Privation. Journal of Child Psychology and Psychiatry 39, 465-476.

Rutter M, Bailey A, Lord C (2003) SCQ. The Social Communication Questionnaire. Torrance, CA: Western Psychological Services. 
Rutter M, Kreppner J, Croft C, Murin M, Colvert E, Beckett C, Castle J, Sonuga-Barke E (2007) Early adolescent outcomes of institutionally deprived and non-deprived adoptees. III. Quasi-autism. Journal of Child Psychology and Psychiatry 48, 1200-1207.

Rutter M, O'Connor TG (2004) Are There Biological Programming Effects for Psychological Development? Findings From a Study of Romanian Adoptees. Developmental Psychology 40, 81-94.

Sheppard DP, Bruineberg JP, Kretschmer-Trendowicz A, Altgassen M (2018) Prospective memory in autism: theory and literature review. Clinical Neuropsychologist 32, 748-782.

Sonuga-Barke EJ, Kennedy M, Kumsta R, Knights N, Golm D, Rutter M, Maughan B, Schlotz W, Kreppner J (2017) Child-to-adult neurodevelopmental and mental health trajectories after early life deprivation: the young adult follow-up of the longitudinal English and Romanian Adoptees study. The Lancet 389, 1539-1548.

Sonuga- Barke EJS, Cortese S, Fairchild G, Stringaris A (2016) Annual Research Review: Transdiagnostic neuroscience of child and adolescent mental disorders - differentiating decision making in attention-deficit/hyperactivity disorder, conduct disorder, depression, and anxiety. Journal of Child Psychology and Psychiatry 57, 321-349.

Sorensen L, Sonuga-Barke E, Eichele H, van Wageningen H, Wollschlaeger D, Plessen KJ (2017) Suboptimal Decision Making by Children With ADHD in the Face of Risk: Poor Risk Adjustment and Delay Aversion Rather Than General Proneness to Taking Risks. Neuropsychology 31, 119-128.

Stevens SE, Sonuga-Barke EJS, Kreppner JM, Beckett C, Castle J, Colvert E, Groothues C, Hawkins A, Rutter M (2008) Inattention/overactivity following early severe institutional deprivation: Presentation and associations in early adolescence. Journal of Abnormal Child Psychology 36, 385-398.

Talbot K-DS, Mueller U, Kerns KA (2018) Prospective memory in children with attention deficit hyperactivity disorder: a review. Clinical Neuropsychologist 32, 783-815.

Vasileva M, Petermann F (2018) Attachment, Development, and Mental Health in Abused and Neglected Preschool Children in Foster Care: A Meta-Analysis. Trauma, Violence, \& Abuse 19, 443-458.

Wade M, Fox NA, Zeanah CH, Nelson CA (2019) Long-term effects of institutional rearing, foster care, and brain activity on memory and executive functioning. Proceedings of the National Academy of Sciences 116, 1808-1813.

Wechsler D (2011) Wechsler Abbreviated Scale of Intelligence, Second Edition (WASI-II). San Antonio, TX: NCS Pearson.

Wilcox RR (2016) Introduction to Robust Estimation and Hypothesis Testing. 4 edition Waltham, MA: Academic Press.

Young JC, Widom CS (2014) Long-term effects of child abuse and neglect on emotion processing in adulthood. Child Abuse \& Neglect 38, 1369-1381. 
Table 1

Neuropsychological performance in the non-deprived UK and Romanian adoptees exposed to institutional deprivation.

\begin{tabular}{|c|c|c|c|c|c|c|c|}
\hline \multirow[b]{2}{*}{ Domain } & \multirow[b]{2}{*}{$\mathrm{n}_{\mathrm{UK}} / \mathrm{n}_{\mathrm{RA}}$} & \multirow[b]{2}{*}{$\begin{array}{l}\text { UK } \\
\text { Mean } \\
(\mathrm{SD})\end{array}$} & \multirow[b]{2}{*}{$\begin{array}{l}\text { Rom } \\
\text { Mean } \\
\text { (SD) }\end{array}$} & \multicolumn{2}{|c|}{ Unadjusted } & \multicolumn{2}{|c|}{ Adjusted for IQ } \\
\hline & & & & $\begin{array}{l}\text { Trimmed } \\
\text { Mean } \\
\text { Difference } \\
(95 \% \mathrm{CI})\end{array}$ & $\mathrm{T}_{\gamma}, \xi$ & $\begin{array}{l}\text { Trimmed } \\
\text { Mean } \\
\text { Difference } \\
(95 \% \mathrm{CI})\end{array}$ & $\mathrm{T}_{\gamma}, \xi$ \\
\hline $\mathrm{IQ}^{1}$ & $22 / 70$ & $\begin{array}{l}107.59 \\
(11.96)\end{array}$ & $\begin{array}{l}95.04 \\
(14.07)\end{array}$ & $\begin{array}{l}12.43 \\
(5.85 ; 19.00)\end{array}$ & $3.63^{* *} \mathrm{o}, \xi=.57$ & N/A & N/A \\
\hline $\begin{array}{l}\text { Prospective } \\
\text { Memory }^{1}\end{array}$ & $22 / 69$ & $\begin{array}{l}44.73 \\
(4.43)\end{array}$ & $\begin{array}{l}40.29 \\
(7.01)\end{array}$ & $\begin{array}{l}4.21 \\
(2.03 ; 6.38)\end{array}$ & $3.80^{* * *} \mathrm{o}, \xi=.57$ & $\begin{array}{l}2.99 \\
(1.30 ; 4.68)\end{array}$ & $3.36^{* *} \mathrm{o}, \xi=.51$ \\
\hline $\begin{array}{l}\text { Proactive } \\
\text { Inhibition }^{1}\end{array}$ & $22 / 64$ & $\begin{array}{l}42.30 \\
(27.01)\end{array}$ & $\begin{array}{l}25.06 \\
(27.31)\end{array}$ & $\begin{array}{l}21.12 \\
(6.64 ; 35.61)\end{array}$ & $3.10^{* *} \mathrm{o}, \xi=.49$ & $\begin{array}{l}16.33 \\
(1.69 ; 30.98)\end{array}$ & $2.18^{*}, \xi=.41$ \\
\hline $\begin{array}{l}\text { Commission } \\
\text { Errors }^{2}\end{array}$ & $22 / 64$ & $\begin{array}{l}7.77 \\
(4.99)\end{array}$ & $\begin{array}{l}9.64 \\
(6.63)\end{array}$ & $\begin{array}{l}-1.70 \\
(-4.53 ; 1.13)\end{array}$ & $-1.17 \xi=0.21$ & $\begin{array}{l}-1.23 \\
(-4.35 ; 1.89)\end{array}$ & $-.83, \xi=0.14$ \\
\hline $\begin{array}{l}\text { Decision- } \\
\text { making quality }{ }^{1}\end{array}$ & $22 / 66$ & $\begin{array}{l}11.51 \\
(1.89)\end{array}$ & $\begin{array}{l}10.34 \\
(2.41)\end{array}$ & $\begin{array}{l}1.21 \\
(0.29 ; 2.13)\end{array}$ & $2.56^{* \mathrm{o}}, \xi=.42$ & $\begin{array}{l}0.87 \\
(0 ; 1.75)\end{array}$ & $1.95, \xi=.29$ \\
\hline $\begin{array}{l}\text { Emotion } \\
\text { Recognition }^{\# 1}\end{array}$ & $22 / 64$ & $\begin{array}{l}67.42 \\
(12.17) \\
\end{array}$ & $\begin{array}{l}59.38 \\
(13.41) \\
\end{array}$ & $\begin{array}{l}7.96 \\
(1.61 ; 14.31) \\
\end{array}$ & $2.51^{*} \mathrm{o}, \xi=.41$ & $\begin{array}{l}3.53 \\
(-2.13 ; 9.19) \\
\end{array}$ & $1.27, \xi=.20$ \\
\hline
\end{tabular}

CI: confidence interval; IQ: intelligent quotient; ${ }^{*} \mathrm{p}<.05,{ }^{* *} \mathrm{p}<.01 ;{ }^{\circ}$ Significant after FDR-correction.

$\mathrm{T}_{\gamma}$ : Robust comparison of means via the Yuen-Welch method with bootstrapped confidence intervals (Wilcox, 2016), $\xi$ : robust exploratory measure of effect size, $\xi=.15$ (small effect), $\xi=.35$ (moderate effect), $\xi=.50$ (large effect) (Wilcox, 2016); ${ }^{\#}$ Emotion recognition is based on the aggregate score across all negative emotions

${ }^{1}$ Lower values indicate relative impairment

${ }^{2}$ Higher values indicate relative impairment 



\section{Table 2}

Symptoms of ADHD and ASD in the non-deprived UK and Romanian adoptees exposed to institutional deprivation and correlations between ASD and

ADHD symptoms and neuropsychological performance across the five domains investigated.

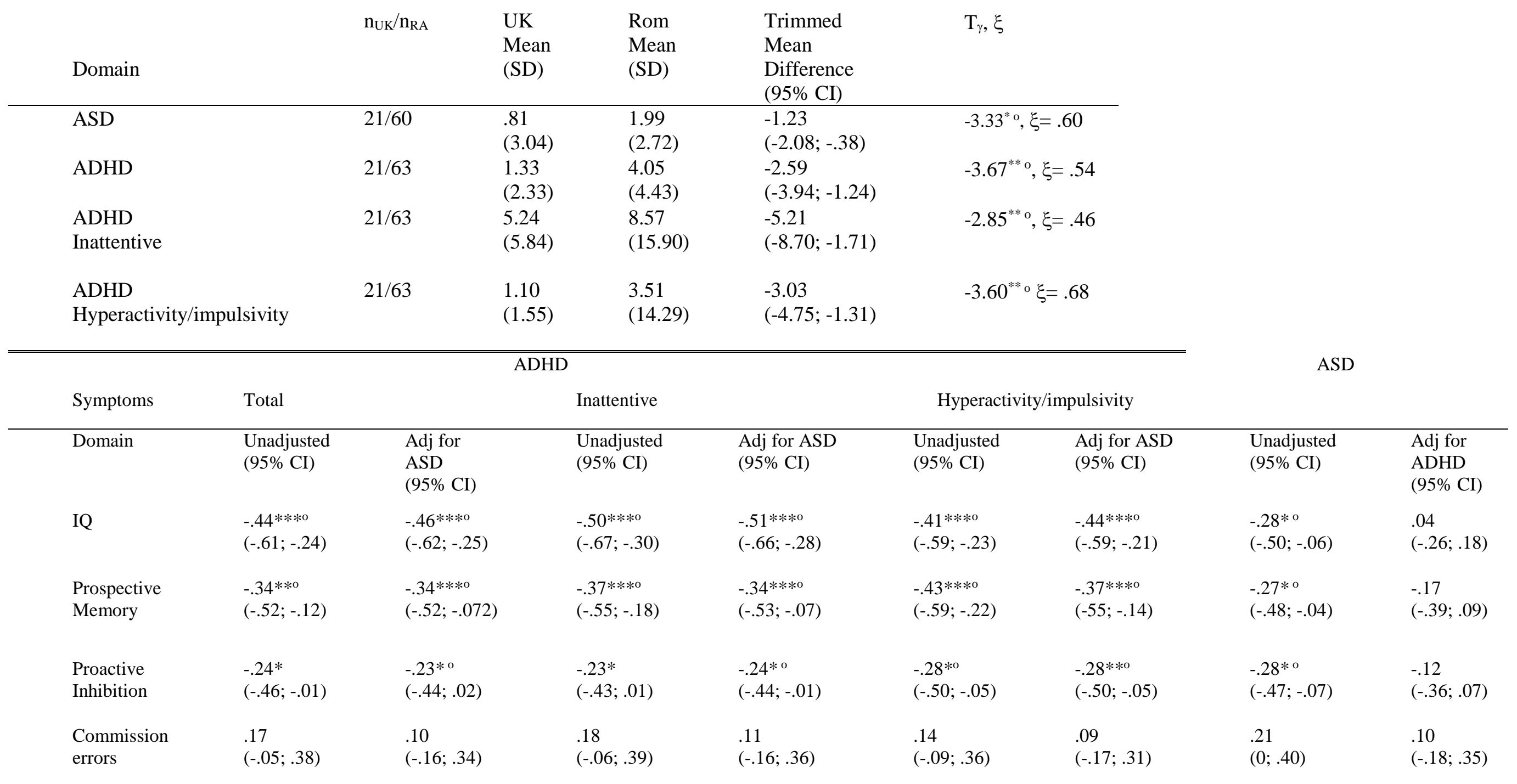




\begin{tabular}{|c|c|c|c|c|c|c|c|c|}
\hline $\begin{array}{l}\text { Risk } \\
\text { Proneness }\end{array}$ & $\begin{array}{l}-.03 \\
(-.26 ; .19)\end{array}$ & $\begin{array}{l}-.03 \\
(-.26 ; .21)\end{array}$ & $\begin{array}{l}.03 \\
(-.20 ; .24)\end{array}$ & $\begin{array}{l}.01 \\
(-.21 ; .26)\end{array}$ & $\begin{array}{l}.05 \\
(-.19 ; .28)\end{array}$ & $\begin{array}{l}.05 \\
(-.15 ; .28)\end{array}$ & $\begin{array}{l}.11 \\
(-.09 ; .31)\end{array}$ & $\begin{array}{l}.03 \\
(-.18 ; .30)\end{array}$ \\
\hline $\begin{array}{l}\text { Decision- } \\
\text { making } \\
\text { quality }\end{array}$ & $\begin{array}{l}-.20 \\
(-.42 ; .03)\end{array}$ & $\begin{array}{l}-.22 * 0 \\
(-.43 ; .03)\end{array}$ & $\begin{array}{l}-.16 \\
(-.39 ; .07)\end{array}$ & $\begin{array}{l}-.18 * \\
(-.40 ; .09)\end{array}$ & $\begin{array}{l}-.08 \\
(-.32 ; .15)\end{array}$ & $\begin{array}{l}-.13 \\
(-.33 ; .13)\end{array}$ & $\begin{array}{l}-.13 \\
(-.37 ; .11)\end{array}$ & $\begin{array}{l}-.10 \\
(-.37 ; .15)\end{array}$ \\
\hline $\begin{array}{l}\text { Emotion } \\
\text { recognition } \#\end{array}$ & $\begin{array}{l}-.30 * * 0 \\
(-.48 ;-.10)\end{array}$ & $\begin{array}{l}-.30 * * \mathrm{o} \\
(-.47 ; .03)\end{array}$ & $\begin{array}{l}-.29 * \\
(-.49 ;-.06)\end{array}$ & $\begin{array}{l}-.28 * * \mathrm{o} \\
(-.49 ;-.04)\end{array}$ & $\begin{array}{l}-.22 \\
(-.43 ;-.01)\end{array}$ & $\begin{array}{l}-.22 * 0 \\
(-.42 ; .02)\end{array}$ & $\begin{array}{l}-.32 * * \text { о } \\
(-.52 ;-.09)\end{array}$ & $\begin{array}{l}-.17 \\
(-.40 ; .07)\end{array}$ \\
\hline
\end{tabular}

Adj.: adjusted; ${ }^{\circ}$ Significant after FDR-correction. \#Emotion recognition based on the aggregate score for all negative emotions.

Partial Spearman correlations with bootstrapped 95\% confidence intervals (1000 bootstraps) with and without controlling for symptoms of ASD (or ADHD). 
Table 3

The results of the regression analysis illustrating that the association between deprivation and ADHD symptoms was carried by deprivation-related effects on IQ and prospective memory.

\begin{tabular}{lccccc} 
& & & \multicolumn{3}{c}{ 95\% CIs (bias-corrected) } \\
\cline { 2 - 6 } & $\mathrm{B}$ & $\mathrm{SE} \mathrm{B}$ & $\mathrm{p}$ & Lower & Upper \\
\hline & & & & & \\
Step 1 & & & & & \\
Constant & 1.33 & .52 & .013 & .41 & 2.43 \\
Deprivation & $2.78(1.09)$ & .76 & .001 & 1.31 & 4.27 \\
& & & & & \\
Step 2 & & & & & \\
Constant & 10.09 & 2.87 & .001 & 5.55 & 16.51 \\
Deprivation & $1.93(.70)$ & .80 & .029 & .23 & 3.56 \\
PM & $-.20(-.18)$ & .06 & .003 & -.33 & -.10 \\
& & & & & \\
Step 3 & & & & & \\
Constant & 18.77 & 3.87 & .001 & 12.22 & 27.90 \\
Deprivation & $.92(.08)$ & .80 & .254 & -.68 & 2.56 \\
PM & $-.13(-.13)$ & .06 & .036 & -.27 & -.02 \\
IQ & $-.11(-.09)$ & .03 & .001 & -.17 & -.05 \\
\hline
\end{tabular}

Note: Step 1: $\mathrm{R}^{2}=.09 ;$ Step 2: $\mathrm{R}^{2}=.18 ;$ Step 3: $\mathrm{R}^{2}=.30$; Robust Bs are provided in brackets.

PM: prospective memory; IQ: intelligence quotient; CIs: confidence intervals, SE: standard error 


\section{Supplementary Material}

\section{Supplement 1}

Supplementary Table 1:

Attrition analysis: Comparison of the current sample (ERABIS) with the original sample utilising data available at age 6 years

\begin{tabular}{|c|c|c|c|c|c|c|c|c|c|c|}
\hline \multirow[b]{2}{*}{ Domain } & \multicolumn{6}{|c|}{ Romanian adoptees (NIR excluded) } & \multicolumn{4}{|c|}{ UK adoptees } \\
\hline & $\begin{array}{c}\mathrm{N} \\
\text { (org/ERABIS) }\end{array}$ & $\begin{array}{l}\text { All } \\
\text { (SD) }\end{array}$ & $\begin{array}{c}\text { ERABIS } \\
\text { Mean } \\
(\mathrm{SD}) \\
\end{array}$ & $\begin{array}{c}\text { Trimmed Mean } \\
\text { Difference } \\
(95 \% \mathrm{CI})\end{array}$ & $\mathrm{T}_{\gamma}, \xi$ & $\begin{array}{c}\mathrm{N} \\
\text { (org/ERABIS) }\end{array}$ & $\begin{array}{c}\text { All } \\
\text { (SD) }\end{array}$ & $\begin{array}{c}\text { ERABIS } \\
\text { Mean } \\
(\mathrm{SD}) \\
\end{array}$ & $\begin{array}{c}\text { Trimmed Mean } \\
\text { Difference } \\
(95 \% \text { CI })\end{array}$ & $\mathrm{T}_{\gamma}, \xi$ \\
\hline Deprivation duration in months & $144 / 70$ & $\begin{array}{c}16.25 \\
(11.38)\end{array}$ & $\begin{array}{c}15.89 \\
(10.89)\end{array}$ & $\begin{array}{c}.91 \\
(-4.01 ; 5.83)\end{array}$ & $.35, .04$ & NA & NA & NA & NA & NA \\
\hline IQ & $134 / 67$ & $\begin{array}{c}89.37 \\
(21.21)\end{array}$ & $\begin{array}{c}91.74 \\
(19.35)\end{array}$ & $\begin{array}{c}-5.32 \\
(-13.12 ; 2.48)\end{array}$ & $-1.38, .18$ & $52 / 23$ & $\begin{array}{l}105.29 \\
(17.81)\end{array}$ & $\begin{array}{l}103.70 \\
(21.60)\end{array}$ & $\begin{array}{c}-.55 \\
(-13.54 ; 12.43)\end{array}$ & $-.09, .04$ \\
\hline ADHD symptoms & $137 / 69$ & $\begin{array}{l}.75 \\
(.58)\end{array}$ & $\begin{array}{l}.76 \\
(.57)\end{array}$ & $\begin{array}{c}-.04 \\
(-.27 ; .19)\end{array}$ & $-.31, .03$ & $51 / 23$ & $\begin{array}{l}.50 \\
(.48)\end{array}$ & $\begin{array}{l}.53 \\
(.52)\end{array}$ & $\begin{array}{c}-.02 \\
(-.33 ; .29)\end{array}$ & $-.15, .04$ \\
\hline ASD symptoms & $135 / 68$ & $\begin{array}{l}2.66 \\
(2.27)\end{array}$ & $\begin{array}{c}2.29 \\
(1.84)\end{array}$ & $\begin{array}{c}.51 \\
(-.28 ; 1.31)\end{array}$ & $1.28, .18$ & $50 / 23$ & $\begin{array}{c}1.81 \\
(1.97)\end{array}$ & $\begin{array}{c}1.57 \\
(2.06)\end{array}$ & $\begin{array}{c}.80 \\
(-.34 ; 1.93)\end{array}$ & $1.40, .28$ \\
\hline
\end{tabular}

CI: confidence interval; IQ: intelligent quotient; ${ }^{*} \mathrm{p}<.05,{ }^{* *} \mathrm{p}<.01 ;$

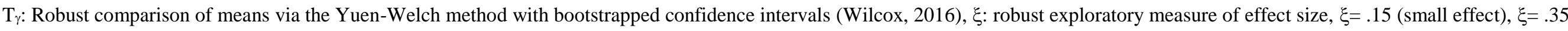

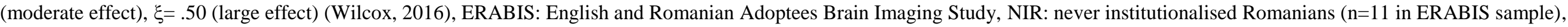

NA: not applicable,

org: original ERA sample 
Supplementary Figure 1:

Attrition analysis (Romanian adoptees only)
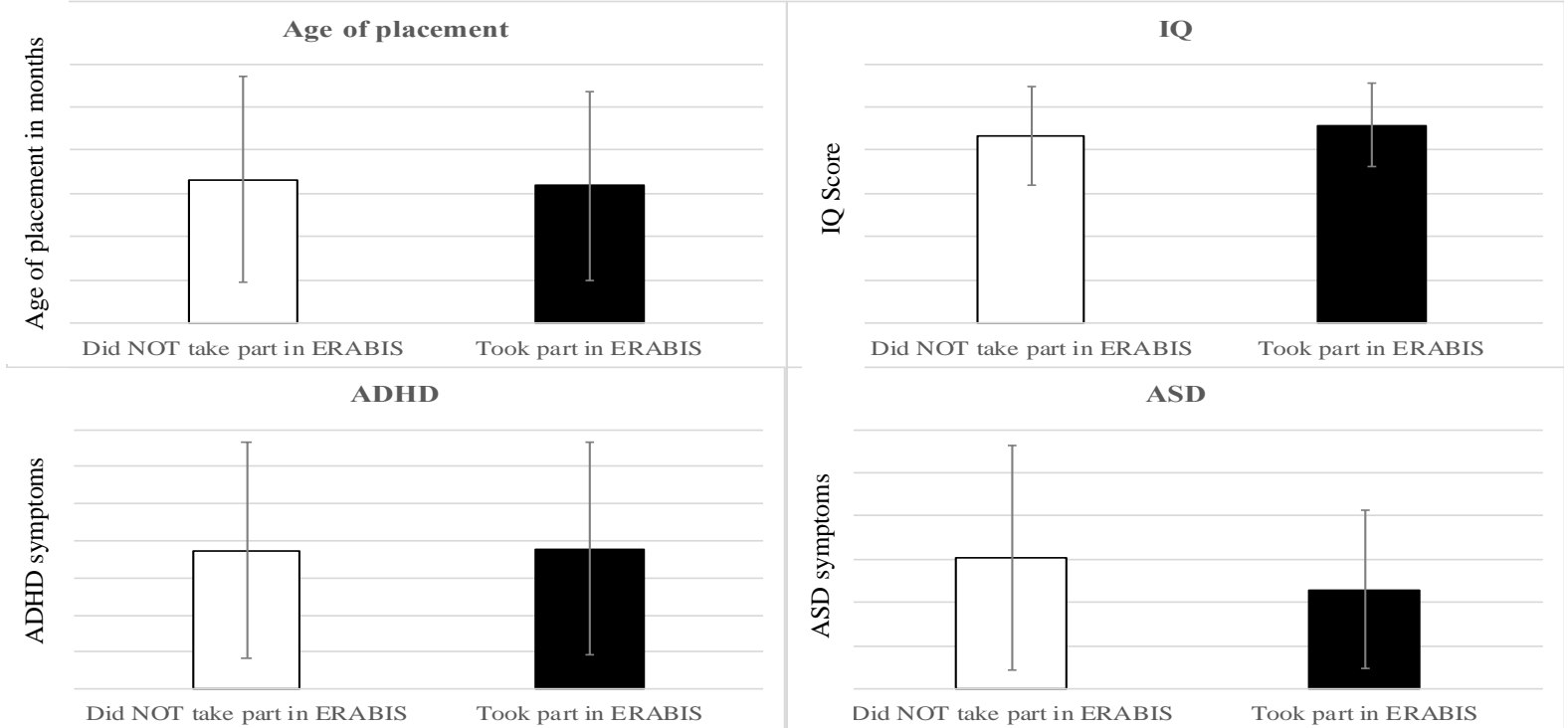

ERABIS: English and Romanian Adoptees Brain Imaging Study

Please note that Romanian adoptees without a history of deprivation have been removed from this figure ( $\mathrm{n}=21$ in original sample) 
$\underline{a}$
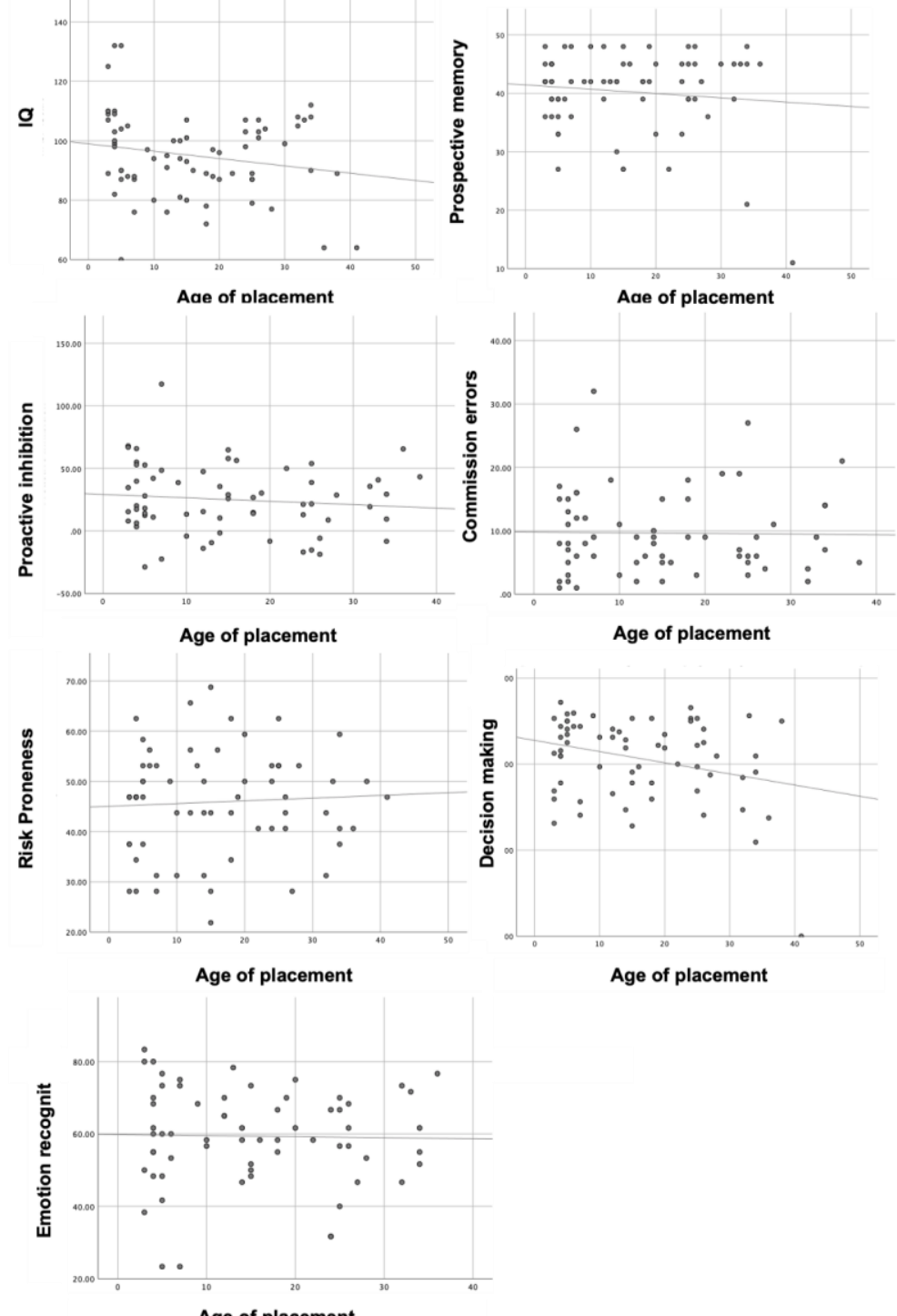

Age of placement 


\section{Supplement 2: Risky-choice task}

Supplementary Table 2:

Probabilities, comparison trials and expected values of the eight experimental trials of the risky choice task.

\begin{tabular}{|c|c|c|c|c|c|}
\hline \multirow[t]{2}{*}{ Trial type } & \multicolumn{2}{|l|}{ Risky Choice Wheel } & \multicolumn{2}{|c|}{ Control Choice Wheel } & \multirow[t]{2}{*}{ Expected value } \\
\hline & win/ probability & loss/ probability & win/ probability & loss/ probability & \\
\hline 1 & $.25 /+20$ & $.75 /-80$ & $.50 /+10$ & $.50 /-10$ & -55 \\
\hline 2 & $.25 /+80$ & $.75 /-80$ & $.50 /+10$ & $.50 /-10$ & -40 \\
\hline 3 & $.25 /+20$ & $.75 /-20$ & $.50 /+10$ & $.50 /-10$ & -10 \\
\hline 4 & $.75 /+20$ & $.25 /-80$ & $.50 /+10$ & $.50 /-10$ & -5 \\
\hline 5 & $.25 /+80$ & $.75 /-20$ & $.50 /+10$ & $.50 /-10$ & 5 \\
\hline 6 & $.75 /+20$ & $.25 /-20$ & $.50 /+10$ & $.50 /-10$ & 10 \\
\hline 7 & $.75 /+80$ & $.25 /-80$ & $.50 /+10$ & $.50 /-10$ & 40 \\
\hline 8 & $.75 /+80$ & $.25 /-20$ & $.50 /+10$ & $.50 /-10$ & 55 \\
\hline
\end{tabular}


Figure 3:

Risky-choice-task

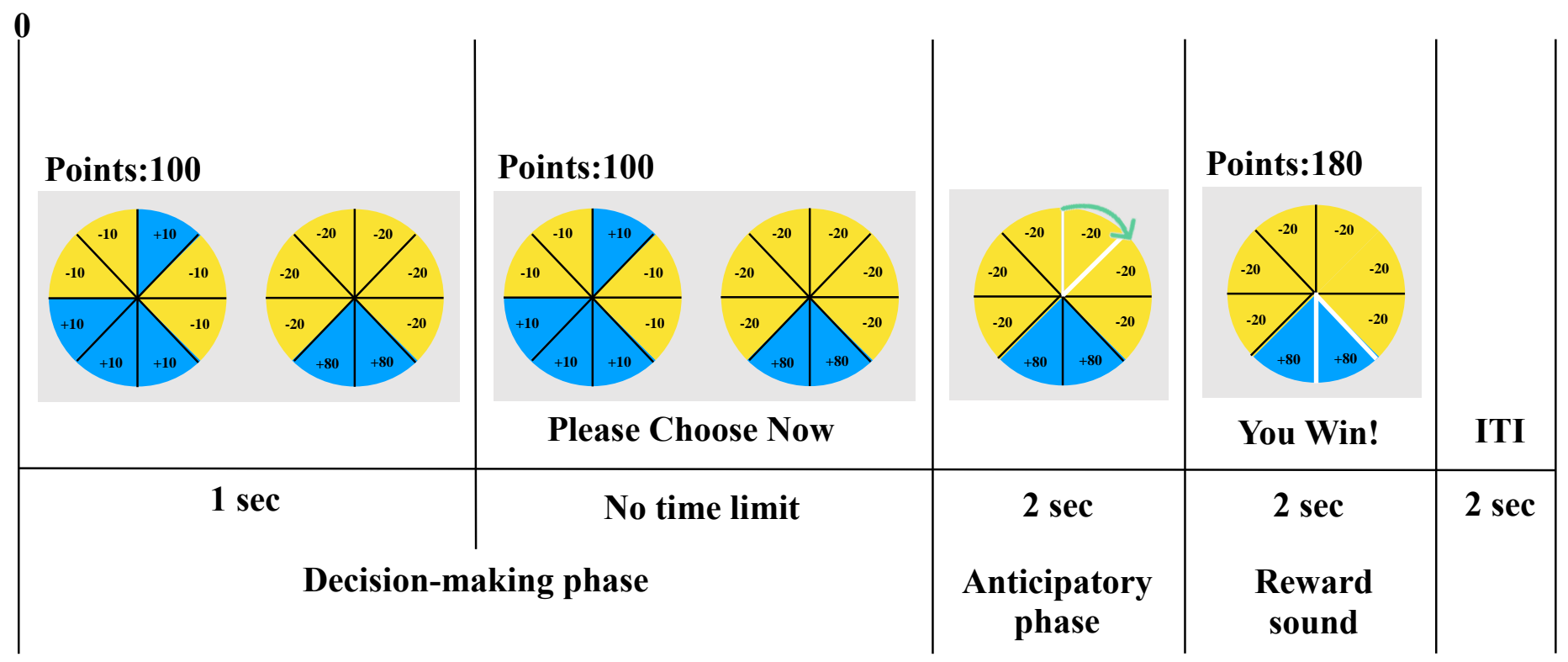

ITI: inter-trial interval 


\section{Supplement 3: Emotion recognition control condition}

Supplementary Table 3: Identification of non-emotional control faces in the two adoptee groups

\begin{tabular}{lllll}
\hline & $\mathrm{n}_{\mathrm{UK}} / \mathrm{n}_{\mathrm{RA}}$ & $\begin{array}{l}\mathrm{UK} \\
\text { Mean } \\
\text { Domain }\end{array}$ & $\begin{array}{l}\text { Rom } \\
\text { Mean } \\
(\mathrm{SD})\end{array}$ & $\begin{array}{l}\text { Trimmed Mean } \\
\text { Difference } \\
(95 \% \mathrm{CI})\end{array}$ \\
\hline Non-emotional faces & $22 / 64$ & 87.22 & 82.62 & $5.96 \quad \begin{array}{l}\mathrm{T}_{\gamma}, \xi \\
(-.38 ; 12.30)\end{array}$ \\
& & $(13.15)$ & $(12.67)$ &
\end{tabular}

Note: $\mathrm{p}=.067$

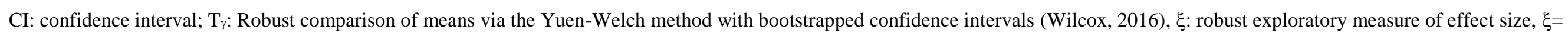

.15 (small effect), $\xi=.35$ (moderate effect), $\xi=.50$ (large effect) (Wilcox, 2016)

Supplementary Table 4: Correlations between the amount of correctly identified non-emotional control faces and symptoms of ASD and ADHD (whole group) and duration of deprivation (Romanian adoptees only)

\begin{tabular}{lcll}
\hline \multicolumn{3}{c}{ Spearman correlations } \\
& \multicolumn{3}{c}{$(95 \%$ bootstrapped and bias corrected confidence interval) } \\
\hline \multirow{3}{*}{ Non-emotional faces } & ADHD & ASD & Deprivation duration (RA only) \\
& $\mathrm{r}=-.12$ & $\mathrm{r}=-.14$ & $\mathrm{r}=-.11$ \\
& $(-.34 ; .13)$ & $(-.37 ; .08)$ & $(-.36 ; .14)$ \\
\hline Note: ADHD: $\mathrm{p}=.311$, ASD: $\mathrm{p}=.117$, Deprivation duration: $\mathrm{p}=.376$ &
\end{tabular}


Supplement 4: Correlations between parent-rated ASD and ADHD symptoms in Romanian adoptees living with their parents and Romanian adoptees living alone/ with their partner

Supplementary Table 5:

Spearman correlations between parent-reported ADHD and ASD symptoms and neuropsychological outcomes as a function of whether the Romanian adoptees were still living with their parents. Fisher's z-tests were used to test for differences in correlation coefficients between adoptees living with their parents and adoptees living on their own or with their partner. Please note that differences in sample size are due to missing data on living situation in the whole sample.

\begin{tabular}{|c|c|c|c|c|c|c|c|c|}
\hline & \multicolumn{2}{|c|}{ All RA } & \multicolumn{2}{|c|}{ RA living with parents } & \multicolumn{2}{|c|}{ RA living with partner/ alone } & \multicolumn{2}{|c|}{ Test statistic } \\
\hline & $\begin{array}{l}\text { ADHD } \\
(95 \% \text { CI })\end{array}$ & $\begin{array}{l}\text { ASD } \\
(95 \% \mathrm{CI})\end{array}$ & $\begin{array}{l}\text { ADHD } \\
(95 \% \mathrm{CI})\end{array}$ & $\begin{array}{l}\text { ASD } \\
(95 \% \text { CI })\end{array}$ & $\begin{array}{l}\text { ADHD } \\
(95 \% \text { CI })\end{array}$ & $\begin{array}{l}\text { ASD } \\
(95 \% \mathrm{CI})\end{array}$ & $\begin{array}{l}\text { ADHD } \\
(95 \% \mathrm{CI})\end{array}$ & $\begin{array}{l}\text { ASD } \\
(95 \% \mathrm{CI})\end{array}$ \\
\hline $\mathrm{N}(\mathrm{IQ} / \mathrm{PM})$ & $63 / 62$ & $60 / 59$ & $23 / 23$ & $22 / 22$ & $37 / 36$ & $35 / 34$ & & \\
\hline IQ & $\begin{array}{l}-.364^{* * o_{0}} \\
(-.561 ;-.127)\end{array}$ & $\begin{array}{l}-.220 \\
(-.470 ; .044)\end{array}$ & $\begin{array}{l}-.259 \\
(-.621 ;-.282)\end{array}$ & $\begin{array}{l}-.276 \\
(-.638 ; .161)\end{array}$ & $\begin{array}{l}-.362 * \\
(-.643 ;-.047)\end{array}$ & $\begin{array}{l}-.173 \\
(-.513 ; .202)\end{array}$ & $\begin{array}{l}\mathrm{z}=.41 \\
(-.369 ; .602)\end{array}$ & $\begin{array}{l}\mathrm{z}=-.38 \\
(-.587 ; .424)\end{array}$ \\
\hline $\begin{array}{l}\text { Prospective } \\
\text { Memory } \\
\text { (PM) }\end{array}$ & $\begin{array}{l}-.259 * \\
(-.459 ;-.026)\end{array}$ & $\begin{array}{l}-.153 \\
(-.415 ; .129)\end{array}$ & $\begin{array}{l}-.300 \\
(-.601 ; .059)\end{array}$ & $\begin{array}{l}.227 \\
(-.205 ; .627)\end{array}$ & $\begin{array}{l}-.201 \\
(-.479 ; .129)\end{array}$ & $\begin{array}{l}-.302 \\
(-.595 ; .018)\end{array}$ & $\begin{array}{l}\mathrm{z}=-.37 \\
(-.574 ; .421)\end{array}$ & $\begin{array}{l}\mathrm{z}=1.89 \\
(-.022 ; .982)\end{array}$ \\
\hline
\end{tabular}

${ }^{\circ}$ Significant after FDR correction for multiple comparisons

Spearman correlations with bootstrapped 95\% confidence intervals (1000 bootstraps). Correlations with Prospective Memory have been adjusted for IQ.

Fisher's z-test with $95 \%$ confidence intervals. 
Supplement 5: Correlations between self-reported emotional problems and neuropsychological performance

Dimensional symptom counts for parent-rated and self-rated emotional problems were created for Generalised Anxiety Disorder and Depression by mapping items from the Conner's Comprehensive Behavior Rating Scale (Conners, 2008) on to DSM-5 (American Psychiatric Association, 2013) symptom domains.

Symptom counts for GAD and Depression were then averaged to create an Emotional problems score (see Golm et al., 2020 for details).

Supplementary Table 6: Spearman correlations with emotional problems (mean score of Emotional Problems Paper score of Generalised Anxiety Disorder and Depression symptoms)

\begin{tabular}{lll}
\hline & \multicolumn{1}{c}{$\begin{array}{c}\text { Emotional problems } \\
\text { Self-rated } \\
(95 \% \mathrm{CI})\end{array}$} & \multicolumn{1}{c}{$\begin{array}{c}\text { Emotional problems } \\
\text { Parent-rated } \\
(95 \% \mathrm{CI})\end{array}$} \\
\hline Prospective memory & -.081 & $-.245^{*}$ \\
& $(-306 ; .145)$ & $(-.451 ;-.010)$ \\
Proactive inhibition & -.122 & -.177 \\
& $(-.339 ; .132)$ & $-.388 ; .066)$ \\
Commission errors & .093 & $(-.220 ; .198)$ \\
& $(-.150 ; .337)$ & .018 \\
Riskprone & -.193 & $(-.211 ; .249)$ \\
& $(-.410 ; .035)$ & -.057 \\
Decision Making & -.198 & $(-.280 ; .154)$ \\
& $(-.442 ; .047))$ & -.158 \\
Facial recognition & $-.231 *$ & $(-.393 ; .080)$ \\
& $(-.444 ;-.013)$ &
\end{tabular}

${ }^{*} \mathrm{p}<.05,{ }^{\circ}$ Significant after FDR correction for multiple comparisons 


\section{Supplement 6: Correlations between neuropsychological outcomes and duration of deprivation}

Supplementary Table 6:

Spearman correlations between neuropsychological outcomes and duration of deprivation in months (Romanian adoptees only)

\begin{tabular}{|c|c|c|c|c|c|c|c|}
\hline & & & (95\% bootst & $\begin{array}{r}\text { Spearman } \\
\text { apped and bias }\end{array}$ & $\begin{array}{l}\text { correlations } \\
\text { corrected co }\end{array}$ & fidence int & rval) \\
\hline Duration of deprivation in months & $\begin{array}{l}\text { IQ } \\
r=-.19 \\
(-.44 ; .08)\end{array}$ & $\begin{array}{l}\text { Prospective } \\
\text { Memory } \\
\mathrm{r}=.06 \\
(-.18 ; .30)\end{array}$ & $\begin{array}{l}\text { Proactive } \\
\text { Inhibition } \\
\mathrm{r}=-.11 \\
(-.37 ; .18)\end{array}$ & $\begin{array}{l}\text { Commission } \\
\text { Errors } \\
\mathrm{r}=.001 \\
(-.27 ; .25)\end{array}$ & $\begin{array}{l}\text { Risk } \\
\text { Proneness } \\
\mathrm{r}=.07 \\
(-.17 ; .28)\end{array}$ & $\begin{array}{l}\text { Decision } \\
\text { Making } \\
-.18 \\
(-.46 ; .10)\end{array}$ & $\begin{array}{l}\text { Emotion Recognition }^{\#} \\
\mathrm{r}=-.06 \\
(-.36 ; .25)\end{array}$ \\
\hline
\end{tabular}

${ }^{*} \mathrm{p}<.05,{ }^{* *} \mathrm{p}<.01 ;{ }^{\#}$ Emotion recognition is based on the aggregate score across all negative emotions 
We thank the reviewers for their thoughtful comments in the submission process and for helping to clarify our thinking and improving the paper.

Reviewer \#2: The authors quantify "Effective proactive inhibition" as "slowing of reaction times to "go" target responses for "possible inhibition" compared to the "never inhibit" cues".

However, what was unclear to me, is why the authors call this RT difference alone "effective proactive inhibition", when this measure does not take into account accuracy for the nogo trials! That is, the whole purpose of inhibition here is to not make an error-of-commision for the nogo trials, so it seems like that would be the most important measure of inhibition, and the measure of whether inhibition was "effective" or not. The RT difference seems to reflect a more general proactive inhibition, which may or may not be effective. Related to this point, it might be better to combine the RT and accuracy data into a combined measure to get at "effective proactive inhibition".

Perhaps the biggest issue though, is that after making a big deal about the RT measure being "effective proactive inhibition" they do also measure and compare groups for commission errors as well. But, the groups do not differ for commission errors, only for their RT measure. The RT difference is an interesting effect in its own right. However, I think it might be worth changing the interpretation a bit, and at the very least, not call it "effective proactive inhibition".

Reply: We thank the reviewer for their thoughtful comment. We indeed only included reaction times from correct responses into the calculation of proactive inhibition, but failed to mention this in the paper. We have now removed the word "effective" and clarified that only correct responses were included. The sentence now reads:

Proactive inhibition was indicated by a slowing of reaction times to correct "go" target responses for "possible inhibition" compared to the "never inhibit" cues. 
The impact of childhood deprivation on adult neuropsychological functioning is associated with ADHD symptom persistence

Dennis Golm ${ }^{1}$, Sagari Sarkar², Nuria K. Mackes ${ }^{3}$, Graeme Fairchild ${ }^{4}$, Mitul A. Mehta ${ }^{5}$, Michael Rutter $^{6}$, ERA Young Adult Follow Up study team* and Edmund J. Sonuga-Barke**3,7

${ }^{1}$ Centre for Innovation in Mental Health, School of Psychology, University of Southampton, UK

2. Cognitive Neuroscience \& Neuropsychiatry Section, University College London.

${ }^{3}$ Department of Child and Adolescent Psychiatry, Institute of Psychiatry, Psychology \& Neuroscience, King's College London, UK

${ }^{4}$ Department of Psychology, University of Bath, UK

${ }^{5}$ Department of Neuroimaging, Institute of Psychiatry, Psychology and Neuroscience, King's College London, UK

${ }^{6}$ MRC Social Genetic \& Developmental Psychiatry Centre, Institute of Psychiatry, Psychology \& Neuroscience, King's College London, UK

${ }^{7}$ Department of Child \& Adolescent Psychiatry, Aarhus University, Denmark.

*The ERA young adult follow-up team is Edmund Sonuga-Barke, Mark Kennedy, Jana Kreppner, Nicky Knights, Robert Kumsta, Barbara Maughan and Wolff Schlotz.

**Correspondence should be addressed to Professor Edmund Sonuga-Barke, Department of Child and Adolescent Psychiatry- P085, Institute of Psychiatry, Psychology and Neuroscience, King's College London, 16 De Crespigny Park, London, SE5 8AF, UK. Email: edmund.sonuga-barke@kcl.ac.uk

Word count: 5403 


\begin{abstract}
Background: Institutional deprivation in early childhood is associated with neuropsychological deficits in adolescence. Using 20-year follow-up data from a unique natural experiment - the largescale adoption of children exposed to extreme deprivation in Romanian institutions in the 1980s -we examined, for the first time, whether such deficits are still present in adulthood and whether they are associated with deprivation-related symptoms of attention-deficit/hyperactivity disorder (ADHD) and autism spectrum disorder (ASD).
\end{abstract}

Methods: Adult neuropsychological functioning was assessed across five domains (inhibitory control, emotion recognition, decision-making, prospective memory and IQ) in 70 previously-institutionalized adoptees (mean age $=25.3,50 \%$ female) and 22 non-deprived UK adoptees (comparison group, mean age $=24.6,41 \%$ female). ADHD and ASD symptoms were assessed using parent-completed questionnaires.

Results: Early institutionalization was associated with impaired performance on all tasks in adulthood. Prospective memory deficits persisted after controlling for IQ. ADHD and ASD symptoms were positively correlated. After controlling for ASD symptoms, ADHD symptoms remained associated with deficits in IQ, prospective memory, proactive inhibition, decision-making quality and emotion recognition. ASD symptoms were not independently associated with neuropsychological deficits when accounting for their overlap with ADHD symptoms. Multiple regression analysis revealed that the link between childhood deprivation and adult ADHD symptoms was statistically explained by deprivationrelated differences in adult IQ and prospective memory.

Conclusions: These results represent some of the most compelling evidence to date of the enduring power of early, time-limited childhood adversity to impair long-term neuropsychological functioning across the lifespan - effects that are linked specifically to deprivation-related adult ADHD symptoms. Keywords: institutional deprivation, childhood neglect, maltreatment, prospective memory, ADHD 
Childhood neglect is associated with long-term negative developmental (Vasileva and Petermann, 2018), mental health (Norman et al., 2012; Vasileva and Petermann, 2018) and neuropsychological outcomes (Kavanaugh et al., 2017). However, the interpretation of such associations is hindered by design limitations common to observational studies. For instance, many studies rely on retrospective reports of neglect (Hardt and Rutter, 2004; Norman et al., 2012) occurring in biological families of individuals either specifically identified or self-selected as a result of the development of mental health problems. This makes it difficult to disentangle early adversity from familial genetic and environmental risk (including continuing adversity) and subsequent psychopathology.

The English and Romanian Adoptees (ERA) study utilizes a unique natural experiment - the largescale adoption of infants and young children from the Romanian institutions after the fall of Ceaușescu's regime in 1989 - with a prospective design, thus addressing some of these methodological problems to strengthen causal inference. Adoptees entered institutions in the first weeks of life and were then exposed to up to 43 months of global deprivation, a particularly severe type of neglect marked by limited cognitive stimulation, minimal social interaction with adult carers, and poor diet and hygiene (Sonuga-Barke et al., 2017). They were subsequently adopted into well-resourced UK families where they received high-quality care. This led to a precisely-timed, sudden and dramatic change in their rearing environment, which was largely determined by historical circumstances. Crucially, this meant that the duration of deprivation exposure was unlikely to be confounded with variations in either genetic or pre-institutional risk and/or post-adoption circumstances. Further, because the adoptees entered the study based on their deprivation exposure, rather than because they displayed the adverse effects of deprivation (e.g., psychopathology), the association between deprivation exposure and neuropsychological impairment can be disentangled from deprivation related psychopathology. 
The ERA study has followed-up the adoptees at ages 4, 6, 11 and 15 years, and most recently in young adulthood (aged 23-25 years). For nearly all of the adoptees, an initial devastating effect of deprivation on development was recorded at the time of adoption. This was followed, for many, by marked recovery by age 6 years (Rutter, 1998). Nevertheless, a substantial minority of adoptees, especially those exposed to $>6$ months deprivation, presented with a heterogeneous yet distinctive pattern of neurodevelopmental problems in comparison to non-deprived adoptees. Most pronounced were symptoms of attention-deficit/hyperactivity disorder (ADHD; Kenne_____et__al._2016)), autism spectrum disorder (ASD; R friendliness and a lack of social boundaries; Kennedy et al. 2017). These problems have persisted to a striking degree through to adulthood, in spite of exposure to positive and nurturing family environments in the intervening period (> 20 years in some cases) (Kennedy et al., 2017; SonugaBarke et al., 2017). This persistence, has led to the hypothesis that these problems are the result of deep-seated changes in underlying neuropsychological processes (Rutter and O’Connor, 2004; McCrory et al., 2017; Nelson et al., 2019). In support of this hypothesis, deprivation-specific neurodevelopmental difficulties were in many cases accompanied by cognitive impairment, as indexed by low IQ - although a degree of catch-up in IQ has occurred across childhood and adolescence (Sonuga-Barke et al., 2017). Extended childhood deprivation was associated with deficits on neuropsychological tests of social cognition and executive function at age 11 (Colvert et al., 2008c). Furthermore, we have recently reported MRI data confirming deprivation-related reductions in total brain volume and regional alterations in frontal and temporal lobes (Mackes et al., 2020).

Our study is the first to provide data on the persistence of adverse neuropsychological effects into adulthood, as all previous research on post-institutionalized individuals have included either children or adolescents (Colvert et al., 2008c, 2008a; Bos et al., 2009; McDermott et al., 2013, 2013; Merz et al., 2013; Moulson et al., 2015; Almas et al., 2016; Bick et al., 2017; Wade et al., 2019). We also investigated the relationship between deprivation-related effects on neuropsychological functioning 
and two of the hallmark neurodevelopmental effects of institutional deprivation - ADHD and ASD symptoms. DSE was not included in this analysis because it was limited almost exclusively to those individuals with extended deprivation.

We selected four neuropsychological domains for investigation, in addition to IQ. This selection process was guided by evidence from previous waves of the ERA study, clinical interviews with the adult adoptees performed during the most recent assessment wave (the ERA Young Adult Follow-up), and prior evidence suggesting a link between these domains and early neglect, childhood maltreatment in general and/or ADHD or ASD symptoms. These domains were: (i) Inhibitory control - this is impaired in individuals who have experienced institutional deprivation (McDermott et al., 2013; Merz et al., 2013) and is associated with both ADHD (Huizenga et al., 2009; Lipszyc and Schachar, 2010; Miller et al., 2012; Miranda-Casas et al., 2013) and ASD (Geurts et al., 2014). At the age 11 wave of the ERA Study, inhibitory control deficits statistically mediated the relationship between deprivation and ADHD symptoms (Colvert et al., 2008c). It is now recognized that inhibitory control can be separated into two elements - proactive inhibition, the recruitment of executive resources in preparation to withhold a response before its initiation to a target, and reactive inhibition, the ability to stop a response after its initiation in response to a target (Meyer and Bucci, 2016). Proactive and reactive inhibition represent equally important aspects of inhibitory based executive control. However, most tasks are unable to distinguish between these different elements of inhibition. We therefore decided to use a cued Go-NoGo task to isolate proactive inhibition from the conventional analysis of commission errors on non-cued tasks which would index failures of reactive inhibition. To date no studies of proactive inhibition have been conducted in maltreated samples. In children with ADHD (Pani et al., 2013; van Hulst et al., 2018) and ASD (van Hulst et al., 2018), deficits seem to be primarily limited to reactive inhibition. However, adult studies are lacking. (ii) Prospective memorydeficits in prospective memory, the ability to remember to undertake an action in the future, were reported by ERA participants during clinical interviews conducted before we designed this study. 
Previous reports suggest that adolescents with a history of maltreatment are impaired in prospective (Lin et al., 2017) and other forms of memory _. Prospective memory has also been found to be impaired in children and adults with ADHD (Fuermaier et al., 2013; Talbot et al., 2018) and ASD (Sheppard et al., 2018). (iii) Emotion recognition impairments are commonly reported in children and adolescents following institutional deprivation (Colvert et al., 2008b; Nelson et al., 2013; Moulson et al., 2015; Bick et al., 2017; Doretto and Scivoletto, 2018). Individuals with ADHD and ASD also display emotion recognition deficits (Lozier et al., 2014; Borhani and Nejati, 2018). (iv) Decisionmaking about outcomes varying in amount and probability is impaired in maltreated children (Guyer $e t$ al., 2006), children with a history of early stress (Hanson et al., 2016; Birn et al., 2017), and adolescents exposed to institutional deprivation (Mehta et al., 2010). Additionally, it is impaired in individuals with ADHD (Sonuga- Barke et al., 2016; Sorensen et al., 2017) though findings are inconsistent in ASD (Dillon et al., 2009; Carlisi et al., 2017).

We studied performance on neuropsychological tests measuring these domains to address five questions in relation to institutional deprivation and the associated outcomes of ADHD and ASD symptoms:

(i) Is time-limited institutional deprivation related to neuropsychological deficits in early adulthood?

(ii) If present, were these effects most pronounced in those individuals exposed to the most extended periods of deprivation?

(iii) Are these effects simply due to deficits in general cognitive ability (IQ), which we know exist in the extended deprivation group?

(iv) Are deprivation-related ADHD and ASD symptoms associated with neuropsychological deficits and are these effects independent of one another? 
(v) Is the association between childhood institutional deprivation and adult ADHD and/or ASD symptoms explained by the former's association with adult IQ or other neuropsychological deficits?

\section{Methods and Materials}

\section{Participants}

The current sample included 70 adult Romanian adoptees who experienced between 3 and 41 months of institutional deprivation (mean age $=25.3$ years; $50 \%$ female) and a control group of 23 UK neverinstitutionalized adoptees (mean age $=24.6$ years; $39 \%$ female) - representing $49 \%$ and $44 \%$ of the original sample, respectively. To assess whether selective attrition had occurred, we compared all ERABIS participants ( $\mathrm{n}=93)$ with ERA participants who did not take part in ERABIS $(\mathrm{n}=103)$ in terms of deprivation status, IQ and ADHD and ASD symptoms at age 6 years. The two groups did not differ on any variable (robust t-tests with $20 \%$ trimmed means and bias-corrected bootstrapped confidence intervals; ps>.16; see Supplement 1). One UK adoptee was excluded from all subsequent analyses due to low IQ $(<60)$, reducing the UK adoptee group to 22 participants (mean age $=24.6,41 \%$ female).

\section{Measures}

Inhibitory control. In the cued Go/No-Go (GNG) task (Criaud et al., 2012), participants had to either press a button when a "go" target (white circle) was present or inhibit their response to a "no-go" target (white "X") presented on each trial in the center of the computer screen. The response interval was $1000 \mathrm{~ms}$ (stimulus presentation duration: 950ms, 50ms inter-stimulus interval). Two conditions, each with 108 trials, were compared to isolate an individual's ability to mobilize and maintain resources required for an upcoming inhibitory response (i.e., proactive inhibition). A "possible 
inhibition" trial was indicated by a pre-target red cross (+) cue $(2000 \mathrm{~ms}$ or $6000 \mathrm{~ms})$ to indicate that either a "no-go or "go" target would be presented (both n=48). This cue alerted the participant to prepare to inhibit their response. This was compared to a control "never inhibit" condition where a white cross (+) indicated that only "go" targets $(\mathrm{n}=81)$ would be presented and thus proactive mobilization of inhibitory resources was not required. Proactive inhibition was indicated by a slowing of reaction times to correct "go" target responses for "possible inhibition" compared to the "never inhibit" cues. The remaining trials in each condition ( $n=12$ for "possible inhibition" and $n=27$ for the "never inhibit") were null trials in which no target was presented. The dependent variables were proactive inhibition and commission errors - the failure to withhold a reaction to a stop target. Prospective memory. The Memory for Intentions Screening Test (MIST) (Raskin, 2009) involved a word-search puzzle as a distractor task during which participants were requested to remember to respond to instructions delivered throughout the task either at specified times or to pre-determined events at either short ( 2 minutes) or long (15 minutes) intervals. Responses could be made in response to verbal (e.g. "In two minutes, please tell me two things you forgot to do this week") or action-based cues (e.g. "When I give you a red pen, sign your name on your paper."). The dependent variable was the total sum score with higher scores indicating better prospective memory functioning.

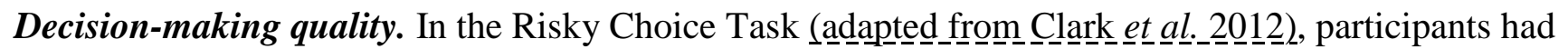
to choose between two roulette wheels offering different sums of money and different probabilities of receiving a gain versus a loss. Each wheel was divided into 8 segments, each segment contained a number depicting a possible win (+) or loss (-) amount - marked in different colors. The amount available to be won or lost and the probability of winning (indexed by the number of win versus loss segments) was systematically varied across trials. At the beginning of each new block, participants started with 100 points. On each trial after a 1000ms delay, "please choose now" appeared on the screen and the participant had to select a wheel. There was no time limit. After the choice was made, the selected wheel was presented on its own and a ticker span around the wheel for $2000 \mathrm{~ms}$ before landing on a segment. The amount of money won or lost was then displayed for $2000 \mathrm{~ms}$ and added to 
or subtracted from the total score, followed by a 2000ms inter-stimulus-interval. Eight trial types involved a choice between a control gamble and an experimental gamble. The experimental gamble could result in either a larger gain or loss with varying probabilities ( 25 or $75 \%$ ), while the control gamble could result in either a small gain or loss (see supplement 2). Overall, there were 76 trials divided into four blocks. There were two dependent variables: Decision-making quality - the probability of choosing the most valuable wheel -was computed by first weighing the probability with which each participant chose the experimental gamble with its expected value and then averaging across those newly computed values to create a single score $\left(\bar{x}=\frac{1}{n}\left(\sum\left(F_{i} * E_{i}\right)\right)\right)$. Risk proneness - the average probability of choosing the experimental gamble $\left(\bar{x}=\frac{1}{n}\left(\sum\left(F_{i}\right)\right)\right.$.

Emotion recognition. The emotion recognition task was taken from the EMOTICOM battery (Bland et al., 2016), which had two conditions. In the experimental condition, one of four emotional faces (happy, sad, anger or fear; each $\mathrm{n}=21$ ) was presented for $\sim 500 \mathrm{~ms}$ in the center of the screen and participants selected the emotional label (happy, sad, anger or fear) that best described it. The dependent variable was the number of correctly identified expressions expressed as a percentage. Because they were highly correlated (rsspearman $\geq .34$, all ps $\leq .001$ ) the scores for individual negative emotions (anger, sadness, fear) were combined to produce a single emotion recognition score. The recognition score for happy faces was excluded as it did not correlate with the negative emotion recognition scores (rsspearman $\leq .04$, all ps $\geq$.703). During the control condition neutral faces of individuals aged across the lifespan (child, young adult, middle-aged or elderly; each $n=4$ ) were presented, and participants were required to assign age labels to each stimulus (child, young adult, middle aged or elderly). As there were no effects of deprivation or ADHD/ASD symptoms on performance on the age recognition task (all ps $\geq .057$, see supplement 3 ), we present only the results for the negative emotion trials from the condition.

Cognitive ability. IQ was assessed using the Wechsler Abbreviated Scale of Intelligence (Wechsler, 2011), which consists of 4 subscales - two verbal -(vocabulary and similarities) and two performance (block design and matrix reasoning). 
ADHD and ASD symptoms. Parents reported on participants' ADHD symptoms using the two ADHD subscales of the Conners Behavior Rating Scales, a reliable and well-validated instrument (Conners et al., 2011). Ten items measured DSM-5-based inattention symptoms and 10 items assessed hyperactivity/impulsivity symptoms. Parents reported on ASD symptoms using a 15-item version of the Social Communication Questionnaire (SCQ; Rutter, Bailey, \& Lord, 2003), recently adapted for use with adults (Kennedy et al., 2016, 2017). It has 3 scales: social reciprocal interaction, social communication and repetitive and stereotyped behavior (see Sonuga-Barke et al., 2017 for the items retained). All items were answered on a "yes/no" basis. ADHD and ASD parent reports were chosen over self-reports for two reasons despite the fact that many young people were not living at home at the time of assessment. First, because there are doubts about the validity of self-reports of ADHD symptoms (Du Rietz et al., 2016) and ASD (Pearl_et_al.__2017); Second, to maintain continuity with previous analyses in the ERA study (Stevens et al., 2008; Kennedy et al., 2017; Sonuga-Barke et al., 2017). Crucially, there was no difference in correlations between symptoms and neuropsychological test performance for those living and those not living at home (see supplement 4).

\section{Procedure}

Clinical data (including parent-report) were collected during home visits to the families as part of the ERA Young Adult Follow-up (described in Kennedy et al. 2016). Neuropsychological data were collected at the Centre for Neuroimaging Sciences, King's College London, as part of the ERA Brain Imaging Study. Neuropsychological testing was undertaken by trained researchers as part of an 8-hour assessment conducted either over two consecutive days or one day depending on participants' preferences and perceived capacity. Completion of the tasks described above took approximately 2 hours, and the task order was varied in order to reduce the impact of order effects. We asked participants to abstain from cigarettes and caffeinated drinks on the testing day and, if prescribed stimulant medication, for 24 hours before testing. In addition to a lunch break, breaks were provided as required by the participant. Participants provided written informed consent before the ERA and ERABIS assessments. Ethical approval for ERABIS was obtained from the University of 
Southampton's Ethics Committee and the Camberwell and St Giles NHS Research Ethics Committee (14/LO/0477). Ethical approval for the ERA Young Adult Follow-up was obtained from the University of Southampton's Ethics Committee.

\section{Statistical analysis}

SPSS 25 (IBM Corp, 2017) and R 3.3 and R 3.6.1 (R Core Team, 2016, 2019) utilizing the WSR2 package (robust tests) and the RVAideMemoire package (e.g. partial Spearman correlations) were used for data analysis. All analyses were False Discovery Rate (FDR) corrected for multiple comparisons (Benjamini and Hochberg, 1995). First, robust t-tests (Wilcox, 2016) using 20\% trimmed means and bias-corrected bootstrapped confidence intervals (1000 bootstraps as recommended

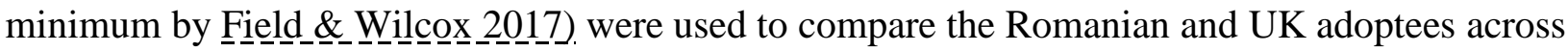
neuropsychological domains. Second, we used Spearman correlations with bootstrapped confidence intervals (to ensure a high level of stringency we used 1000 bootstraps) to examine links between duration of deprivation and neuropsychological performance. Third, to test whether observed effects could be explained by deficits in general cognitive ability, we used a robust regression method to regress IQ onto the neuropsychological scores and then compared the residuals of the neuropsychological scores. Fourth, we examined the associations between neuropsychological outcomes and ASD and ADHD symptom dimensions and their independence from each other using partial Spearman correlations with bootstrapped confidence intervals (1000 bootstraps; minimum number of bootstraps recommended by developer), adjusting for effects of ASD symptoms on the association between ADHD-related symptoms and neuropsychological function and vice versa. Finally, we tested whether the link between childhood deprivation and adult ADHD and/or ASD symptoms was explained by the former's association with adult neuropsychological performance (including IQ) using stepwise multiple regression. Deprivation status was included in step 1. All neuropsychological variables shown to be independently related to deprivation in the above analyses were then introduced at subsequent steps - one at a time - to assess their independent contribution to explaining the link between deprivation and symptom outcomes. The outcome variables were ADHD 
and/or ASD symptom scores, depending on whether they showed an independent association with neuropsychological functioning.

\section{Results}

Relative to non-deprived adoptees, Romanian adoptees had lower IQs, and displayed deficits in proactive inhibition, prospective memory, decision-making quality and emotion recognition $(\mathrm{p}<.05$, Table 1). The effects ranged from moderate to large in size for significant differences according to Wilcox (Wilcox, 2016). Duration of deprivation was not significantly correlated with any neuropsychological outcome within the Romanian group $\left(\mathrm{r}_{\text {Spearman }}=-.19\right.$ to $\mathrm{r}_{\text {Spearman }}=.07$, all $\mathrm{ps} \geq .112$; see supplement 6). Only the group effect for prospective memory remained significant after adjusting for IQ ( $<$ <.05, FDR; see Table 1). Table 2 reports the group differences for ADHD and ASD symptoms and correlations between ASD symptoms ADHD symptoms (and the ADHD subdimensions of inattention and hyperactivity/impulsivity) and neuropsychological test performance. A history of early deprivation had a moderate to large effect on the occurrence of neurodevelopmental symptoms in adulthood. ADHD symptoms were associated with lower IQ and deficits in prospective memory (moderate correlation) and emotion recognition (small correlation). When ASD symptoms were controlled for, all correlations with ADHD symptoms reported above remained significant and additional correlations with impaired decision-making quality and proactive inhibition emerged. ASD symptoms correlated with low IQ and impairment in prospective memory, proactive inhibition and emotion recognition. However, after controlling for ADHD symptoms none of these correlations remained significant. After FDR-correction, neuropsychological test performance was not significantly correlated with either self or parent-rated young adult emotional problems in any measured domain (see supplement 5). 
Only IQ and prospective memory met the criteria for predictors, and only ADHD symptoms met the criteria for outcomes, in the multiple regression analysis (Table 3). There was a strong association between deprivation status and adult ADHD symptoms when the former was introduced alone in step 1. prospective memory was introduced into the model in step 2. It was significantly associated with ADHD symptoms independent of deprivation status. Although deprivation status was still significantly associated with ADHD symptoms, the effect was substantially reduced in this case. IQ was then introduced into the model in step 3. Both IQ and prospective memory were significantly associated with ADHD symptoms - independently of one another. The association between deprivation and ADHD symptoms was no longer significant in this case. This suggests that the link between deprivation and ADHD symptoms was fully accounted for by the former variable's links with IQ and prospective memory.

\section{Discussion}

The ERA Study has shown that extended institutional deprivation experienced in early childhood has a long-term impact on neurodevelopmental outcomes in adulthood - with adult ADHD, ASD and DSE symptoms especially pronounced (Sonuga-Barke et al., 2017). Here we explore the long-term impact of deprivation on neuropsychological performance, and investigate whether deprivation-related neurodevelopmental outcomes are related to neuropsychological deficits, by studying links between deprivation and adult neuropsychological function across a range of domains predicted to be: (i) affected by deprivation; and (ii) linked to deprivation-specific neurodevelopmental problems. These domains were proactive inhibition, emotion recognition, decision-making quality and prospective memory - as well as general cognitive ability (indexed by IQ). There were several noteworthy findings. 
The first major finding was that early childhood institutional deprivation was associated with impairment in young adulthood across a broad range of neuropsychological domains - IQ, prospective memory, proactive inhibition, decision-making quality and emotion recognition. Analysis of the residuals obtained after regressing out IQ showed that, for emotion recognition, proactive inhibition, and decision-making quality these associations were attributable to deprivation-related deficits in general cognitive ability (i.e., IQ). However, this was not the case for prospective memory. It has been previously shown that IQ co-varies with a wide range of neuropsychological functions (Diaz-Asper $e t$ al., 2004) and our results confirm this for proactive inhibition, decision-making quality and emotion recognition in previously institutionalized young adults. Although it may not be surprising that the effect of deprivation on proactive inhibition is accounted for by lower IQ, our observation that this also contributed to group differences in emotion recognition was somewhat unexpected (see Bland et al. 2016). While our previous assessment at the age 11 follow-up (Colvert et al., 2008b) and a metaanalysis (Luke and Banerjee, 2013) support the existence of emotion recognition deficits in institutionally-deprived children and adolescents, many previous studies did not directly test the hypothesis that such deficits were part of a more general pattern of adversity-related cognitive impairment. One longitudinal study found that IQ mediated the effects of maltreatment on emotion recognition in adulthood (Young and Widom, 2014). This suggests that effects of maltreatment on emotion recognition - especially in adulthood - are small and, at least partly, reflect reductions in general cognitive ability, as indexed by IQ. The only domain of neuropsychological performance where no impact of institutional deprivation was observed was risk-proneness - there was no evidence that Romanian adoptees were either more risk seeking, or risk averse, than the UK adoptee comparison group. While few studies have looked at the more general effects of maltreatment on this form of decision-making quality, there are suggestions that more general social disadvantage may increase levels of risk taking (Petridou et al., 1997). The current findings may help to explain why extended deprivation is not associated with engagement in risky behaviors such as substance abuse in the ERA sample (manuscript in preparation). 
The association between IQ and institutional deprivation reported here, and its role in driving the effects of institutional deprivation on specific neuropsychological deficits in adulthood, appears to be at odds with evidence of almost complete remission of cognitive impairment by adulthood in the most severely deprived Romanian adoptees (those exposed to $>6$ months of deprivation (Sonuga-Barke $e t$ $a l ., 2017)$. On possibility is that lower IQ cases were selectively retained in ERABIS. However, our selective attrition analysis did not support this over-representation of lower IQ individuals in the ERABIS sample. However, IQ was included as a continuous measure in the current paper, instead of the categorical definition of cognitive impairment $(\mathrm{IQ}<80)$ in our previous reported finding of IQ deficits remitting with age. This suggests that, despite the observed recovery from cognitive impairment - with previously impaired individuals who had experienced extended deprivation moving into the normal range (i.e., above IQ above 80) - average IQ remained significantly lower in the Romanian adoptees.

The second major finding of note is that the severity of neuropsychological deficits in the Romanian adoptees was unrelated to the duration of deprivation. On the face of it, this is surprising given the step-like duration-related effects that have been reported previously by us for neurodevelopmental disorders such as ADHD and the remarkable persistence of such impairments from childhood to adulthood (Sonuga-Barke et al., 2017). Interestingly, in the Bucharest Early Intervention Project deprivation duration was also unrelated to the cognitive outcomes of memory performance and executive function in a group of Romanian children ( $~ 8$ years of age) with a history of institutionalization compared to never institutionalized children (Bos et al., 2009). The difference between the effects of deprivation on neurodevelopmental/clinical outcomes as reported previously, on one hand, and neuropsychological outcomes reported here on the other, suggests a complex and nondeterministic relationship between neuropsychological deficits (largely accounted for by IQ in this study) and clinical outcomes. This moves us away from simple causal models in which deprivation 
impairs neuropsychological functioning, which in turn drives disorder in a direct fashion (Morton and Frith, 1995). In fact, it would seem that neuropsychological deficits, at least as measured in adulthood, display an all-or-nothing relationship with institutional deprivation - with even children who suffered deprivation for a relatively short amount of time (i.e. 3 months) experiencing a negative effect on later functioning. Despite this, these children are almost completely indistinguishable from the nondeprived UK adoptees in terms of neurodevelopmental and clinical problems (Sonuga-Barke et al., 2017).

Third, neuropsychological performance across a number of domains was associated with ADHD but not ASD symptoms (once ADHD symptoms were controlled for). The finding of ADHD-related prospective memory deficits (Talbot et al., 2018) is consistent with the general neuropsychological literature on ADHD. It constituted the only neuropsychological domain that was related to both institutional deprivation and ADHD symptoms in univariate analyses, apart from IQ. Crucially, the multiple regression analysis suggested that the association between childhood deprivation and adult ADHD symptoms was fully explained by the link between deprivation and IQ and prospective memory - with each of these neuropsychological domains making an independent contribution. Prior research has identified similar deficits in prospective memory in adults with idiopathic (nondeprivation related) ADHD (Fuermaier et al., 2013, 2017; Altgassen et al., 2014; Talbot et al., 2018) that may be restricted to time-based prospective memory tasks (Altgassen et al., 2014). This suggests a degree of neuropsychological equivalence between deprivation- and non-deprivation-related ADHD symptoms, although the fact that the combination of deprivation, IQ and prospective memory explained $30 \%$ of the variance in ADHD symptoms provides support for a strong environmental influence on the neuropsychological underpinnings of ADHD in this sample. Relevant to this, a recent meta-analysis demonstrated working memory deficits in clinical and non-clinical samples of adults who had experienced early life stress (Goodman et al., 2019). 
The lack of correlations between ASD symptoms and neuropsychological performance was surprising given the literature suggesting that ASD is related to deficits in all of the domains assessed here (Geurts et al., 2014; Lozier et al., 2014; Carlisi et al., 2017; Sheppard et al., 2018). There are a number of possible explanations for this finding. First, deprivation-related ASD symptoms may be neuropsychologically distinct from ASD symptoms in non-deprived samples. Second, the current analysis focused on ASD symptoms as a dimension, rather than on individuals who met clinical cutoffs - so the severity of the ASD symptoms may not have been sufficient to lead to neuropsychological deficits and only a small number of individuals presented with high levels of ASD symptoms in the current sample. Finally, while the symptoms were rated through a validated questionnaire, this may not be sufficient to record the full extent to which individuals display features of ASD which would require a clinical assessment.

The present study had several distinctive features and strengths. In particular, it employed a natural experimental design to disentangle the impact of early, time-limited deprivation from the confounding effects of genetic and environmental risk factors that are frequently present in studies of maltreated children. It included a relatively large sample of severely deprived individuals with known durations of deprivation. As part of the ERA study we have also followed up a comparison group of nondeprived UK adoptees and they were included here to control for the effects of adoption per se. This allowed the effects to be studied in a design that reduces the risk of confounding by genetic factors or ongoing adversity. The study was also subject to several limitations. First, for practical reasons (i.e. time considerations) it could only focus on the range of neuropsychological domains presented here. Tasks measuring constructs such as Theory of Mind and temporal discounting would have been valuable additions given earlier evidence from the ERA study (Colvert et al., 2008c). The fact that all neuropsychological assessments were cross-sectional vis-à-vis clinical measures necessarily, limits our interpretation with regard to the causal relationships between neuropsychological performance and ADHD symptoms. Furthermore, we used a dimensional approach to analyzing ADHD and ASD 
symptoms and did not attempt to categorize individuals according to 'clinical' cut-offs. This is consistent with suggestions that ADHD should be viewed as a dimensional construct rather than a categorical diagnosis (McLennan, 2016). Third, the study lacked a non-deprived Romanian comparison group which limited our ability to disentangle effects of institutional care from other socio-economic disadvantages that Romanians were subject to in the harsh conditions of the 1980s. Nevertheless, the Bucharest Early Intervention Project included such a comparison group and still found children with a history of institutionalization to perform worse on neuropsychological tasks (Bos et al., 2009; Almas et al., 2016; Wade et al., 2019). The use of one source of information about ADHD and ASD information is also a potential limitation especially as we were reliant on parent ratings for both individuals who lived at home and those that had left home. However, as mentioned above our analysis showed no difference in parent ratings between these two groups. Finally, although this is an unusually large sample of such severely deprived individuals, it still provides only limited statistical power. It is therefore possible that we were unable to detect some important, though statistically small, effects. This constraint is particularly relevant to the multiple regression analyses, which typically require large sample sizes.

In conclusion, time-limited severe deprivation in early childhood has enduring effects on neuropsychological performance in young adulthood across a range of domains including prospective memory, proactive inhibition, decision-making quality and emotion recognition - but only the deficit in prospective memory was independent from deprivation-related effects on IQ. ADHD symptoms were related to a range of neuropsychological deficits, but only prospective memory explained variance beyond an influence of IQ. This is the first study of prospective memory deficits and their relationship to neurodevelopmental symptoms in previously institutionalized individuals. Such effects were observed over 20 years later, despite adoptees living with well-resourced and supportive families in the intervening period, demonstrating the long-term impact of adverse experiences during sensitive periods of development. 


\section{Acknowledgements}

We thank the families who took part in the study - this research would not have been possible without their continued support and dedication. The study team acknowledges the support of the National Institute for Health Research Clinical Research Network (NIHR CRN). We also thank Niall Bourke for his assistance with data collection and Laura Archer for her preparatory work on the Go-NoGo data.

\section{Financial support}

The Young Adult Follow-up was funded by the Economic and Social Research Council (E.S-B., RES062-23-3300). The Brain Imaging Study was funded by the Medical Research Council (E.S-B., M.M., G.F., MR/K022474/1). This study represents independent research that was part funded by the National Institute for Health Research (NIHR) Biomedical Research Centre at South London and Maudsley NHS Foundation Trust and King's College London.

\section{Conflicts of interest}

None.

\section{Ethical standards}

The authors assert that all procedures contributing to this work comply with the ethical standards of the relevant national and institutional committees on human experimentation and with the Helsinki Declaration of 1975, as revised in 2008. 


\section{References}

Almas AN, Degnan KA, Nelson CA, Zeanah CH, Fox NA (2016) IQ at age 12 following a history of institutional care: Findings from the Bucharest Early Intervention Project. Developmental psychology 52, $1858-1866$.

Altgassen M, Kretschmer A, Kliegel M (2014) Task Dissociation in Prospective Memory Performance in Individuals With ADHD. Journal of Attention Disorders 18, 617-624.

Benjamini Y, Hochberg Y (1995) Controlling the False Discovery Rate: A Practical and Powerful Approach to Multiple Testing. Journal of the Royal Statistical Society. Series B (Methodological) 57, 289300.

Bick J, Luyster R, Fox NA, Zeanah CH, Nelson CA (2017) Effects of early institutionalization on emotion processing in 12-year-old youth. Development and Psychopathology 29, 1749-1761.

Birn RM, Roeber BJ, Pollak SD (2017) Early childhood stress exposure, reward pathways, and adult decision making. Proceedings of the National Academy of Sciences 114, 13549-13554.

Bland AR, Roiser JP, Mehta MA, Schei T, Boland H, Campbell-Meiklejohn DK, Emsley RA, Munafo MR, Penton-Voak IS, Seara-Cardoso A, Viding E, Voon V, Sahakian BJ, Robbins TW, Elliott R (2016) EMOTICOM: A Neuropsychological Test Battery to Evaluate Emotion, Motivation, Impulsivity, and Social Cognition. Frontiers in Behavioral Neuroscience 10.

Borhani K, Nejati V (2018) Emotional face recognition in individuals withattention-deficit/hyperactivity disorder: a review article. Developmental Neuropsychology 43, 256-277.

Bos KJ, Fox N, Zeanah CH, Nelson CA (2009) Effects of early psychosocial deprivation on the development of memory and executive function. Frontiers in Behavioral Neuroscience $\mathbf{3}$.

Carlisi CO, Norman L, Murphy CM, Christakou A, Chantiluke K, Giampietro V, Simmons A, Brammer M, Murphy DG, Mataix-Cols D, Rubia K (2017) Shared and Disorder-Specific Neurocomputational Mechanisms of Decision-Making in Autism Spectrum Disorder and ObsessiveCompulsive Disorder. Cerebral Cortex 27, 5804-5816.

Clark L, Li R, Wright CM, Rome F, Fairchild G, Dunn BD, Aitken MRF (2012) Risk-avoidant decision making increased by threat of electric shock. Psychophysiology 49, 1436-1443.

Colvert E, Rutter M, Beckett C, Castle J, Groothues C, Hawkins A, Kreppner J, O'connor TG, Stevens S, Sonuga-Barke EJS (2008a) Emotional difficulties in early adolescence following severe early deprivation: Findings from the English and Romanian adoptees study. Development and Psychopathology 20.

Colvert E, Rutter M, Beckett C, Castle J, Groothues C, Hawkins A, Kreppner J, O'connor TG, Stevens S, Sonuga-Barke EJS (2008b) Emotional difficulties in early adolescence following severe early deprivation: Findings from the English and Romanian adoptees study. Development and Psychopathology 20.

Colvert E, Rutter M, Kreppner J, Beckett C, Castle J, Groothues C, Hawkins A, Stevens S, SonugaBarke EJS (2008c) Do Theory of Mind and Executive Function Deficits Underlie the Adverse Outcomes Associated with Profound Early Deprivation?: Findings from the English and Romanian Adoptees Study. Journal of Abnormal Child Psychology 36, 1057-1068. 
Conners CK, Pitkanen J, Rzepa SR (2011) Conners Comprehensive Behavior Rating Scale. In Encyclopedia of Clinical Neuropsychology, pp 678-680 Springer, New York, NY.

Criaud M, Wardak C, Ben Hamed S, Ballanger B, Boulinguez P (2012) Proactive Inhibitory Control of Response as the Default State of Executive Control. Frontiers in Psychology 3.

Diaz-Asper CM, Schretlen DJ, Pearlson GD (2004) How well does IQ predict neuropsychological test performance in normal adults? Journal of the International Neuropsychological Society 10, 82-90.

Dillon DG, Holmes AJ, Birk JL, Brooks N, Lyons-Ruth K, Pizzagalli DA (2009) Childhood Adversity Is Associated with Left Basal Ganglia Dysfunction During Reward Anticipation in Adulthood. Biological Psychiatry 66, 206-213.

Doretto V, Scivoletto S (2018) Effects of Early Neglect Experience on Recognition and Processing of Facial Expressions: A Systematic Review. Brain Sciences 8, 10.

Du Rietz E, Cheung CHM, McLoughlin G, Brandeis D, Banaschewski T, Asherson P, Kuntsi J (2016) Self-report of ADHD shows limited agreement with objective markers of persistence and remittance. Journal of Psychiatric Research 82, 91-99.

Field AP, Wilcox RR (2017) Robust statistical methods: A primer for clinical psychology and experimental psychopathology researchers. Behaviour Research and Therapy 98, 19-38.

Fuermaier ABM, Tucha L, Koerts J, Aschenbrenner S, Westermann C, Weisbrod M, Lange KW, Tucha O (2013) Complex Prospective Memory in Adults with Attention Deficit Hyperactivity Disorder. Plos One 8, e58338.

Fuermaier ABM, Tucha L, Koerts J, Weisbrod M, Lange KW, Aschenbrenner S, Tucha O (2017) Effects of methylphenidate on memory functions of adults with ADHD. Applied Neuropsychology: Adult 24, 199-211.

Geurts HM, van den Bergh SFWM, Ruzzano L (2014) Prepotent Response Inhibition and Interference Control in Autism Spectrum Disorders: Two Meta-Analyses. Autism Research 7, 407-420.

Goodman JB, Freeman EE, Chalmers KA (2019) The relationship between early life stress and working memory in adulthood: A systematic review and meta-analysis. Memory 27, 868-880.

Guyer AE, Kaufman J, Hodgdon HB, Masten CL, Jazbec S, Pine DS, Ernst M (2006) Behavioral Alterations in Reward System Function: The Role of Childhood Maltreatment and Psychopathology. Journal of the American Academy of Child \& Adolescent Psychiatry 45, 1059-1067.

Hanson JL, Albert D, Iselin A-MR, Carre JM, Dodge KA, Hariri AR (2016) Cumulative stress in childhood is associated with blunted reward-related brain activity in adulthood. Social Cognitive and Affective Neuroscience 11, 405-412.

Hardt J, Rutter M (2004) Validity of adult retrospective reports of adverse childhood experiences: review of the evidence. Journal of Child Psychology and Psychiatry 45, 260-273.

Huizenga HM, van Bers BMCW, Plat J, van den Wildenberg WPM, van der Molen MW (2009) Task Complexity Enhances Response Inhibition Deficits in Childhood and Adolescent AttentionDeficit/Hyperactivity Disorder: A Meta-Regression Analysis. Biological Psychiatry 65, 39-45. 
van Hulst BM, de Zeeuw P, Vlaskamp C, Rijks Y, Zandbelt BB, Durston S (2018) Children with ADHD symptoms show deficits in reactive but not proactive inhibition, irrespective of their formal diagnosis. Psychological Medicine 1-7.

Kavanaugh BC, Dupont-Frechette JA, Jerskey BA, Holler KA (2017) Neurocognitive deficits in children and adolescents following maltreatment: Neurodevelopmental consequences and neuropsychological implications of traumatic stress. Applied Neuropsychology-Child 6, 64-78.

Kennedy M, Kreppner J, Knights N, Kumsta R, Maughan B, Golm D, Rutter M, Schlotz W, SonugaBarke EJS (2016) Early severe institutional deprivation is associated with a persistent variant of adult attention-deficit/hyperactivity disorder: clinical presentation, developmental continuities and life circumstances in the English and Romanian Adoptees study. Journal of Child Psychology and Psychiatry 57, 1113-1125.

Kennedy M, Kreppner J, Knights NH, Kumsta R, Maughan B, Golm D, Hill J, Rutter M, SonugaBarke E (2017) Adult disinhibited social engagement (DSE) in adoptees exposed to extreme institutional deprivation: an examination of its clinical status and functional impact. British Journal of Psychiatry.

Lin P-Z, Bai H-Y, Sun J-W, Guo W, Zhang H-H, Cao F-L (2017) Association between child maltreatment and prospective and retrospective memory in adolescents: The mediatory effect of neuroticism. Child Abuse \& Neglect 65, 58-67.

Lipszyc J, Schachar R (2010) Inhibitory control and psychopathology A meta-analysis of studies using the stop signal task. Journal of the International Neuropsychological Society 16, 1064-1076.

Lozier LM, Vanmeter JW, Marsh AA (2014) Impairments in facial affect recognition associated with autism spectrum disorders: A meta-analysis. Development and Psychopathology 26, 933-945.

Luke N, Banerjee R (2013) Differentiated associations between childhood maltreatment experiences and social understanding: A meta-analysis and systematic review. Developmental Review 33, 1-28.

M Pearl A, M Edwards E, J Murray M (2017) Comparison of self-and other-report of symptoms of autism and comorbid psychopathology in adults with autism spectrum disorder. Contemporary Behavioral Health Care 2.

Mackes NK, Golm D, Sarkar S, Kumsta R, Rutter M, Fairchild G, Mehta MA, Sonuga-Barke EJS, on behalf of the ERA Young Adult Follow-up team (2020) Early childhood deprivation is associated with alterations in adult brain structure despite subsequent environmental enrichment. Proceedings of the National Academy of Sciences 117, 641-649.

Malarbi S, Abu-Rayya HM, Muscara F, Stargatt R (2017) Neuropsychological functioning of childhood trauma and post-traumatic stress disorder: A meta-analysis. Neuroscience and Biobehavioral Reviews $\mathbf{7 2}$, 68-86.

McCrory EJ, Gerin MI, Viding E (2017) Annual Research Review: Childhood maltreatment, latent vulnerability and the shift to preventative psychiatry - the contribution of functional brain imaging. Journal of Child Psychology and Psychiatry 58, 338-357.

McDermott JM, Troller-Renfree S, Vanderwert R, Nelson CA, Zeanah CH, Fox NA (2013) Psychosocial deprivation, executive functions, and the emergence of socio-emotional behavior problems. Frontiers in Human Neuroscience 7, 167.

McLennan JD (2016) Understanding attention deficit hyperactivity disorder as a continuum. Canadian Family Physician 62, 979-982. 

Hyporesponsive Reward Anticipation in the Basal Ganglia following Severe Institutional Deprivation Early in Life. Journal of Cognitive Neuroscience 22, 2316-2325.

Merz EC, McCall RB, Wright AJ, Luna B (2013) Inhibitory Control and Working Memory in PostInstitutionalized Children. Journal of Abnormal Child Psychology 41, 879-890.

Meyer HC, Bucci DJ (2016) Neural and behavioral mechanisms of proactive and reactive inhibition. Learning \& Memory 23, 504-514.

Miller M, Ho J, Hinshaw SP (2012) Executive Functions in Girls with ADHD Followed Prospectively into Young Adulthood. Neuropsychology 26, 278-287.

Miranda-Casas A, Baixauli-Fortea I, Colomer-Diago C, Rosello-Miranda B (2013) Autism and attention deficit hyperactivity disorder: similarities and differences in executive functioning and theory of mind. Revista De Neurologia 57, S177-S184.

Morton J, Frith U (1995) Causal modeling: A structural approach to developmental psychopathology. In Developmental psychopathology, Vol. 1: Theory and methods Wiley series on personality processes , pp 357-390 Oxford, England: John Wiley \& Sons.

Moulson MC, Shutts K, Fox NA, Zeanah CH, Spelke ES, Nelson CA (2015) Effects of early institutionalization on the development of emotion processing: a case for relative sparing? Developmental Science 18, 298-313.

Nelson CA, Westerlund A, McDermott JM, Zeanah CH, Fox NA (2013) Emotion recognition following early psychosocial deprivation. Development and psychopathology 25, 517-525.

Nelson CA, Zeanah CH, Fox NA (2019) How Early Experience Shapes Human Development: The Case of Psychosocial Deprivation. Neural Plasticity 2019, 1676285.

Norman RE, Byambaa M, De R, Butchart A, Scott J, Vos T (2012) The Long-Term Health Consequences of Child Physical Abuse, Emotional Abuse, and Neglect: A Systematic Review and MetaAnalysis. ed. M. Tomlinson PLoS Medicine 9, e1001349.

Pani P, Menghini D, Napolitano C, Calcagni M, Armando M, Sergeant JA, Vicari S (2013) Proactive and reactive control of movement are differently affected in Attention Deficit Hyperactivity Disorder children. Research in Developmental Disabilities 34, 3104-3111.

Petridou E, Zavitsanos X, Dessypris N, Frangakis C, Mandyla M, Doxiadis S, Trichopoulos D (1997) Adolescents in High-Risk Trajectory: Clustering of Risky Behavior and the Origins of Socioeconomic Health Differentials. Preventive Medicine 26, 215-219.

Raskin S (2009) Memory for Intentions Screening Test: Psychometric Properties and Clinical Evidence. vol 10 .

Rutter M (1998) Developmental Catch-up, and Deficit, Following Adoption after Severe Global Early Privation. Journal of Child Psychology and Psychiatry 39, 465-476.

Rutter M, Bailey A, Lord C (2003) SCQ. The Social Communication Questionnaire. Torrance, CA: Western Psychological Services. 
Rutter M, Kreppner J, Croft C, Murin M, Colvert E, Beckett C, Castle J, Sonuga-Barke E (2007) Early adolescent outcomes of institutionally deprived and non-deprived adoptees. III. Quasi-autism. Journal of Child Psychology and Psychiatry 48, 1200-1207.

Rutter M, O'Connor TG (2004) Are There Biological Programming Effects for Psychological Development? Findings From a Study of Romanian Adoptees. Developmental Psychology 40, 81-94.

Sheppard DP, Bruineberg JP, Kretschmer-Trendowicz A, Altgassen M (2018) Prospective memory in autism: theory and literature review. Clinical Neuropsychologist 32, 748-782.

Sonuga-Barke EJ, Kennedy M, Kumsta R, Knights N, Golm D, Rutter M, Maughan B, Schlotz W, Kreppner J (2017) Child-to-adult neurodevelopmental and mental health trajectories after early life deprivation: the young adult follow-up of the longitudinal English and Romanian Adoptees study. The Lancet 389, 1539-1548.

Sonuga- Barke EJS, Cortese S, Fairchild G, Stringaris A (2016) Annual Research Review: Transdiagnostic neuroscience of child and adolescent mental disorders - differentiating decision making in attention-deficit/hyperactivity disorder, conduct disorder, depression, and anxiety. Journal of Child Psychology and Psychiatry 57, 321-349.

Sorensen L, Sonuga-Barke E, Eichele H, van Wageningen H, Wollschlaeger D, Plessen KJ (2017) Suboptimal Decision Making by Children With ADHD in the Face of Risk: Poor Risk Adjustment and Delay Aversion Rather Than General Proneness to Taking Risks. Neuropsychology 31, 119-128.

Stevens SE, Sonuga-Barke EJS, Kreppner JM, Beckett C, Castle J, Colvert E, Groothues C, Hawkins A, Rutter M (2008) Inattention/overactivity following early severe institutional deprivation: Presentation and associations in early adolescence. Journal of Abnormal Child Psychology 36, 385-398.

Talbot K-DS, Mueller U, Kerns KA (2018) Prospective memory in children with attention deficit hyperactivity disorder: a review. Clinical Neuropsychologist 32, 783-815.

Vasileva M, Petermann F (2018) Attachment, Development, and Mental Health in Abused and Neglected Preschool Children in Foster Care: A Meta-Analysis. Trauma, Violence, \& Abuse 19, 443-458.

Wade M, Fox NA, Zeanah CH, Nelson CA (2019) Long-term effects of institutional rearing, foster care, and brain activity on memory and executive functioning. Proceedings of the National Academy of Sciences 116, 1808-1813.

Wechsler D (2011) Wechsler Abbreviated Scale of Intelligence, Second Edition (WASI-II). San Antonio, TX: NCS Pearson.

Wilcox RR (2016) Introduction to Robust Estimation and Hypothesis Testing. 4 edition Waltham, MA: Academic Press.

Young JC, Widom CS (2014) Long-term effects of child abuse and neglect on emotion processing in adulthood. Child Abuse \& Neglect 38, 1369-1381. 


\section{Reply letter}

\section{Re: The impact of childhood deprivation on adult neuropsychological functioning is associated with ADHD symptom persistence}

Dear Dr Smith,

Thank you for giving us the opportunity to revise and resubmit the above paper. We have now addressed the comment made by Reviewer 2 . The change is highlighted in the manuscript. We also uploaded a clean version of the manuscript. Please find our reply to the reviewer's comment below.

All the best,

Dennis Golm \& Edmund Sonuga-Barke on behalf of the ERA Brain Imaging Study Team.

\section{Reviewers' and editor's comments:}

We thank the reviewers for their thoughtful comments in the submission process and for helping to clarify our thinking and improving the paper.

Reviewer \#2: The authors quantify "Effective proactive inhibition" as "slowing of reaction times to "go" target responses for "possible inhibition" compared to the "never inhibit" cues".

However, what was unclear to me, is why the authors call this RT difference alone "effective proactive inhibition", when this measure does not take into account accuracy for the nogo trials! That is, the whole purpose of inhibition here is to not make an error-of-commision for the nogo trials, so it seems like that would be the most important measure of inhibition, and the measure of whether inhibition was "effective" or not. The RT difference seems to reflect a more general proactive inhibition, which may or may not be effective. Related to this point, it might be better to combine the RT and accuracy data into a combined measure to get at "effective proactive inhibition".

Perhaps the biggest issue though, is that after making a big deal about the RT measure being "effective proactive inhibition" they do also measure and compare groups for commission errors as well. But, the groups do not differ for commission errors, only for their RT measure. The RT difference is an interesting effect in its own right. However, I think it might be worth changing the interpretation a bit, and at the very least, not call it "effective proactive inhibition".

Reply: We thank the reviewer for their thoughtful comment. We indeed only included reaction times from correct responses into the calculation of proactive inhibition, but failed to mention this in the paper. We have now removed the word "effective" and clarified that only correct responses were included. The sentence now reads:

Proactive inhibition was indicated by a slowing of reaction times to correct "go" target responses for "possible inhibition" compared to the "never inhibit" cues. 